\title{
Schema-Driven Construction of Future Autobiographical Traumatic Events: The Future Is Much More Troubling Than the Past
}

\author{
David C. Rubin \\ Duke University and Aarhus University
}

\begin{abstract}
Research on future episodic thought has produced compelling theories and results in cognitive psychology, cognitive neuroscience, and clinical psychology. In experiments aimed to integrate these with basic concepts and methods from autobiographical memory research, 76 undergraduates remembered past and imagined future positive and negative events that had or would have a major impact on them. Correlations of the online ratings of visual and auditory imagery, emotion, and other measures demonstrated that individuals used the same processes to the same extent to remember past and construct future events. These measures predicted the theoretically important metacognitive judgment of past reliving and future "preliving" in similar ways. On standardized tests of reactions to traumatic events, scores for future negative events were much higher than scores for past negative events. The scores for future negative events were in the range that would qualify for a diagnosis of posttraumatic stress disorder (PTSD); the test was replicated $(n=52)$ to check for order effects. Consistent with earlier work, future events had less sensory vividness. Thus, the imagined symptoms of future events were unlikely to be caused by sensory vividness. In a second experiment, to confirm this, 63 undergraduates produced numerous added details between 2 constructions of the same negative future events; deficits in rated vividness were removed with no increase in the standardized tests of reactions to traumatic events. Neuroticism predicted individuals' reactions to negative past events but did not predict imagined reactions to future events. This set of novel methods and findings is interpreted in the contexts of the literatures of episodic future thought, autobiographical memory, PTSD, and classic schema theory.
\end{abstract}

Keywords: autobiographical memory, future thought, schema, trauma, posttraumatic stress disorder (PTSD)

I have two goals in this paper. The first is to report novel and surprising empirical data on the construction of future traumatic events, including that future negative events are much more troubling than past events, that the lack of detail noted in future events does not occur in the measures of the emotion and availability of the negative events, that with effort the lacking details can be constructed, but that the troubling nature of future negative events does not increase with these added details. These findings do not follow from current models of future episodic thought and support

This article was published Online First April 22, 2013.

David C. Rubin, Department of Psychology and Neuroscience, Duke University, and Center on Autobiographical Memory Research, Aarhus University, Aarhus, Denmark.

Support for this work was provided by National Institute of Mental Health Grant R01 MH066079 and the Danish National Research Foundation Grant DNRF93. I wish to thank Dorthe Berntsen, Annette Bohn, Samantha Deffler, Hildur Finnbogadóttir, Christin Ogle, David Pillemer, Anna Rasmussen, and those attending the Emory Cognition Project on Future Thought for comments and discussions; Robyn Fivush for first drawing my attention to the important effects of uncertainty in people's future; Samantha Deffler for implementing the computer testing; and Cindy Cho and Najib Jai for help with the categorization of memories.

Correspondence concerning this article should be addressed to David C. Rubin, Department of Psychology and Neuroscience, Duke University, Box 90086, Durham, NC 27708-0086. E-mail: david.rubin@duke.edu the second goal of extending theoretical understanding to more fully include studies of schemata and autobiographical memory, including the role of autobiographical memory in posttraumatic stress disorder (PTSD).

The study of future episodic thought owes its intellectual origins and prominence to Tulving's pioneering work on mental time travel (Tulving, 1983, 1985, 2002). Tulving developed the concept of mental time travel from his own neuropsychological observation of amnesiacs, his distinction between episodic and semantic memory, and a laboratory memory tradition explicitly based on Ebbinghaus (1885/1964). In part because of this history, studies of more complex and real-world events, including autobiographical memory, which were often conducted in Bartlett's (1932) schema theory tradition, were not always fully utilized. Therefore, this paper stresses recent research on autobiographical memory and approaches to schema theory, especially from its development in the 1980s and 1990s. To do this, I rely on applications of autobiographical memory to research on traumatic events to produce results that both extend and contrast with the existing literature.

I begin by briefly reviewing what is known about future episodic thought, referring the reader to more detailed reviews of the key theoretical positions (Berntsen \& Bohn, 2010; Buckner \& Carroll, 2007; D'Argembeau, 2012; Hassabis \& Maguire, 2007; Schacter \& Addis, 2007, 2009; Szpunar, 2010). Then I ask in general terms what ideas could be added, test their usefulness in three experiments, and discuss differences that could affect clinical applications and theory. 


\section{Research Findings From the Future Episodic Thought Literature}

The basic findings on future thought are robust on both the neural and behavioral levels (for reviews, see D'Argembeau, 2012; Miles, in press; Rasmussen, in press; Schacter \& Addis, 2007, 2009; Szpunar, 2010). At the neural level, autobiographical memories and imagined future events are constructed through similar processes that are distributed through large regions of the cortex in areas commonly used in recalling autobiographical memories. There are also differences. Frontal areas that are more involved in construction are often more active during future episodic thought, supporting the idea that more conscious effort is needed in construction, and the level of hippocampal activity can differ (Botzung, Denkova, \& Manning, 2008; Schacter \& Addis, 2007, 2009; Spreng \& Grady, 2010; Spreng, Mar, \& Kim, 2009). However, these differences can be difficult to interpret in terms of current goals, because the future and past constructions are not matched on phenomenological reports or raters' determination of the amount and kind of details. Thus, for instance, if the degree of details in the memories and future events were matched, differences in frontal areas involved in the construction between the past and future might be even larger and differences in the sensory systems that tend to be more active once a memory is constructed might be smaller (Daselaar et al., 2008).

At the behavioral level, there are several consensus conclusions. First, episodic future thought is frequent in terms of both voluntary retrieval (D'Argembeau, Renaud, \& Van der Linden, 2011) and involuntary retrieval (Berntsen \& Jacobsen, 2008; Finnbogadóttir \& Berntsen, 2013), reinforcing the interest being shown in the phenomenon. Second, future events are typically rated as less detailed than past events, consistent with the claim that future events require more effort to construct and thus with equal time or effort will be less detailed (Berntsen \& Bohn, 2010; Berntsen \& Jacobsen, 2008; D’Argembeau \& Van der Linden, 2004, 2006; Larsen, 1998). Third, also consistent with the claim that more effort is required to construct future events, some future events will have even fewer details than other future events. This occurs for constructions in less well known locations or at times further from the present, which can be assumed to be less like current situations (Berntsen \& Bohn, 2010; D’Argembeau \& Van der Linden, 2004; Szpunar \& McDermott, 2008; Trope \& Liberman, 2010; see Spreng \& Levine, 2006, for elegant quantitative evidence that events closer to the present are more accessible). For instance, Miles and Berntsen (2011) found minor differences in sensory vividness with future events that were much closer to the present than their comparison past events.

Fourth, the further an event is into the future or past, the more construction relies on general expectations or schemata (Berntsen \& Bohn, 2010). Fifth, consistent with the idea of more schema relevance in the future, future events are rated as more important or personally significant than past events (Addis, Wong, \& Schacter, 2008; Berntsen \& Bohn, 2010; D’Argembeau \& Van der Linden, 2004; Newby-Clark \& Ross, 2003). Sixth, both past events (Walker, Skowronski, \& Thompson, 2003) and future events are more frequently positive than negative in valence, with an interaction caused by future events being even more positive (Berntsen \& Bohn, 2010; D’Argembeau \& Van der Linden, 2006; Finnbogadóttir \& Berntsen, 2013; Newby-Clark \& Ross, 2003; for a general discussion of the asymmetrical effects of valence, see Taylor, 1991; Taylor \& Brown, 1988; Taylor, Pham, Rivkin, \& Armor, 1998). One exception is D'Argembeau and Van der Linden (2004), which unlike the other studies asked for both positive and negative events. It found the valence of future events to be more extreme than past events in the direction requested rather than finding an overall positivity bias, though little has been made theoretically of this discrepancy.

\section{Related Findings From the Autobiographical Memory Literature}

There are many kinds of future thought; however, future episodic thought is special because the construction of autobiographical events can come with the sense of reliving (or "preliving") and "time travel" that provide what Tulving and colleagues have termed autonoetic consciousness (Tulving, 1983, 1985, 2002; Wheeler, Stuss, \& Tulving, 1997). Future episodic thought is special in another way not usually considered in the future episodic thought literature. For autobiographical memories, unlike most other domains, the future is different than the past because of the emotional impact of the uncertainty of the future. Thus, in addition to cognitive factors, there can be emotions that are more intense for future events. The narratives, or schemata, available to guide the construction of future events foster such increased intensity, as is discussed later.

Over the last few decades, the field of autobiographical memory has developed to offer a theoretical and empirical base that can help in understanding future episodic thought. I begin by briefly noting the forms of organization that are needed to construct a real or imagined autobiographical event. From laboratory studies of cuing autobiographical memories (e.g., Rubin, Schrauf, \& Greenberg, 2003), neuropsychological damage cases (for reviews, see Greenberg \& Rubin, 2003; Rasmussen, in press), and neuroimaging (Cabeza \& St. Jacques, 2007; Hassabis \& Maguire, 2007; Spreng \& Grady, 2010; St. Jacques, 2012; St. Jacques, Botzung, Miles, \& Rubin, 2011; Svoboda, McKinnon, \& Levine, 2006), it is clear that autobiographical memory is not a single behavioral or neural entity; rather, separate systems are involved. These basic systems, which include vision, audition, olfaction, spatial organization, language, narrative reasoning, and emotion, have different neural bases that support the construction of past and future events. From basic understanding of behavior it is known that each of these systems has different functions and often well-studied and different forms of schemata that work with fundamentally different kinds of information (e.g., visual images, odors, emotions). The systems are not specifically for memory but are shared by all cognitive activities. They evolved with the species and develop within individuals to process and remember different aspects of stimuli. For instance, narrative and spatial schemata work together to organize sensory and emotional information, but they do so in different ways. Constructing imagined events and recalling real ones will rely on processes in the same systems, as will the extent to which the constructed events are relived (or "prelived"). The existence of these basic systems and their use in constructing memories are among the best supported findings in cognition and neuroscience (for reviews, see Rubin, 2006, 2012).

Two empirical observations facilitate the study of the contributions of individual systems in the recall and imagination of auto- 
biographical events. The first is that participants' ratings of the extent to which they use each system while they are constructing a memory provide data that are reliable and consistent with other behavior (Rubin, 2006; Rubin et al., 2003). In general, ratings made concurrently with a task, as opposed to after the task is completed, reflect underlying processing involved in ways that produce lawful relations and relate in reasonable ways to objective measures (Ericsson \& Simon, 1993). Moreover, the phenomenological reports obtained from such ratings made while autobiographical memories are being recalled are consistent with levels of activity measured in the underlying neural system (e.g., Daselaar et al., 2008; St. Jacques et al., 2011). For example, when autobiographical memories are reported as having more emotional intensity during an fMRI scan, neural regions involved in emotional intensity are more active and are so in theoretically reasonable time courses during the extended recall process (Daselaar et al., 2008).

The second empirical observation is that an individual's use of each system in constructing memories is stable. This observation allows one to test the hypothesis that the same systems are used to the same relative degree to recall past and to imagine future events. The clearest evidence comes from an experiment by Rubin, Schrauf, and Greenberg (2004). Undergraduates were asked to briefly describe 20 autobiographical memories in one-line descriptions specific enough so that these would cue one and only one event in their lives. Next, they recalled and rated each of their 20 memories on a series of scales, similar to the ones to be used here, that tapped the systems needed to construct autobiographical memories. Two weeks later they were given their own 20 descriptions and asked to recall and rate the memories again. There was stability in each individual's average rating on each scale, even when the averages were calculated on 10 different memories from each session. Correlations for the mean levels of most scales across the two sessions were between .80 and .95 . Here and in the experimental literature in general, however, correlations are expected to be lower. Because fewer than 20 memories are rated, the reliability of each individual's means is lower.

Additional evidence for stable individual differences in the use of basic systems in memory construction comes from studies of PTSD in which both undergraduates chosen to vary widely in PTSD symptoms and community-dwelling volunteers with and without a formal diagnosis of PTSD were asked for word-cued, important, negative, and positive autobiographical memories ( $\mathrm{Ru}-$ bin, Boals, \& Berntsen, 2008; Rubin, Dennis, \& Beckham, 2011). In both studies, PTSD symptom severity correlated with ratings from systems affected by PTSD (e.g., emotion) but not from others (e.g., narrative reasoning and language). This indicates that the ratings vary with (and therefore are stable during) the disorder. There is also research on clinical disorders, including depression (Williams et al., 1996), complicated grief (Maccallum \& Bryant, 2011), PTSD (Brown et al., 2013), and schizophrenia (D’Argembeau, Raffard, \& Van Der Linden, 2008), demonstrating decreases in the specificity of both memories and future constructions in the clinical population, often with substantial correlations between the specificity of individuals' construction in both tasks.

I use these two empirical observations in novel ways. As reviewed here, it is commonly claimed that past and future events are constructed in similar ways. However, the behavioral tests of this claim are indirect. For instance, D'Argembeau and Van der Linden
(2006) reported that people who score highly on individual differences tests of visual imagery also have more visual details in both past and future events but do not directly compare the degree of visual details in their past and future events. In this paper, ratings of degree to which individuals use the processes of the basic systems are correlated to obtain quantitative measures of the extent to which individuals use these processes to the same degree in constructing past and future events. These ratings are then used in multiple regressions to predict reliving and preliving to see if they combine in the same way to account for this key index of autonoetic consciousness and time travel. I also examine the means of these ratings averaged over individuals to examine similarities in the overall level of the use of these processes in constructing past and future events.

\section{Existing Theoretical Accounts of Future Episodic Thought}

A future episodic thought that has not been constructed before cannot be simply recalled; it must be constructed, and it must be constructed using memory. There are two broad categories of how this could be done. One is by combining details of past events; the other is by creating events from general principles abstracted from all of experience and filling in the event with details that may or may not be associated with past events. In describing the constructive episodic simulation hypothesis, Schacter and Addis (2007) postulated a common system for remembering past and imagining future events that "can draw on elements of the past and retain the general sense or gist of what has happened. Critically, it can flexibly extract, recombine and reassemble these elements in a way that allows us to simulate, imagine or 'pre-experience' events that have never occurred" (p. 778). Thus, both gist and elements are available, but, according to the constructive episodic simulation hypothesis, elements of past events are needed. Constructive episodic simulation is "the prevailing conceptual framework" for future episodic thought (Szpunar, 2010, p. 146; see also D’Argembeau \& Mathy, 2011). But as Szpunar (2010), D'Argembeau and Mathy (2011), and others have acknowledged and as Berntsen and Bohn (2010) discussed in detail, "specific future episodes may be constructed without the need to necessarily rely on the contents of episodic memory" (Szpunar, 2010, p. 157). Two separate issues are involved. The first is the relative weight of details and general principles, an issue that has been addressed in the schema literature discussed next and that is investigated here. The second, which is not investigated empirically here, as articulated by Szpunar (2010) and others, is whether episodic memory is needed at all. Once details are separated from their episodic memories, it is unclear how one could tell if their source was general knowledge or elements of unassembled episodic memories unless participants provide insight into their source. When they do, few elements come from past events (D'Argembeau \& Mathy, 2011).

\section{Schema Theory}

To put the current literature in a broader context, consider what is known about remembering a real and imagining a fictitious event, story, drawing, or any other to-be-remembered item. The classic and best supported theory that unites remembering and 
imagination is schema theory, as introduced to cognitive psychology by Bartlett (1932) and developed through hundreds of careful experimental and theoretical studies (for reviews from different perspectives, see Alba \& Hasher, 1983; Brewer \& Nakamura, 1984; Rubin, 1995; Rumelhart, Smolensky, McClelland, \& Hinton, 1986). A schema is "an active organisation of past reactions, or of past experiences, which must always be supposed to be operating in any well-adapted organic response" (Bartlett, 1932, p. 201). Schemata were at times taken to refer only to abstract meaning, gist, or deep processing rather than to surface or shallow processing, but this was neither Bartlett's idea nor a reasonable summary of the data that emerged from testing his ideas (Blaxton, 1989; Bransford, McCarrell, Franks, \& Nitsch, 1977; Rubin, 1995). Rather, schemata can exist for any form of organization appreciated by the individual, including thematic, visual, or even poetic organization.

Bartlett concentrated on memory for real texts and pictures, but imagined instances provide the clearest view of a schema because they do not attempt to recall a single instance. Undergraduates who have learned a set of traditional ballads can generate a new ballad that fits into the learned set (Rubin, Wallace, \& Houston, 1993). Undergraduates can draw a new 20-cent coin that fits into the United States currency (Rubin \& Kontis, 1983) or name a new form of pasta, radioactive element, nonprescription analgesic, or laundry detergent (Rubin, Stoltzfus, \& Wall, 1991). The imagined novel instances follow the general patterns of the domains including both "surface" and "deep" forms of organization. Empirically, they are not based on just one existing instance or even an average of existing properties; rather, they are constructed to follow the same rules, principles, or schemata that would guide the recall of actual instances and produce errors or changes in them (see Rubin, 1995, for a review). Similarly, mathematical modeling of schemata can be based on stored instances, but they must be combined in a nonlinear fashion to produce schema-like behavior (Hintzman, 1986).

In very general terms, the difference between relying on specific instance and more general principles is similar to classic issues of contingency versus rule-based learning and trial and error versus insight problem solving. Here, I rely on the difference between similarity-based and explanation-based learning (Ahn, Brewer, \& Mooney, 1992) from the schema and concept formation literature because it fits best with the autobiographical memory domain of future episodic thought.

Similarity-based learning requires repeated exposure to instances that will form the schema so that similarities can be extracted. Here, the parallel is constructing future episodic events based on recombining details from many instances. Ahn et al. (1992) noted several limitations of this method that are relevant here. Unlike explanation-based learning, similarity-based learning does not take into account the learner's domain knowledge (i.e., general principles or schemata at a more abstract level); therefore, similarity-based learning does not distinguish between explanatory and nonexplanatory information, thus allowing spurious correlations to be learned. Thus, as with future episodic thought, something beyond specific memories of past events is needed. To show the advantages of explanation-based learning, Ahn et al. demonstrated the learning of a schema from a single instance that involves easily accessible social domain knowledge of reciprocity among friends (see also Schank \& Abelson, 1995). Details of how the explanations functioned have been instantiated on computer programs (see Ahn et al., 1992).

The following examples of creating novel instances presented earlier may help clarify differences between recombining existing details and using more general principles. When undergraduates created a name for a new radioactive element, they tended to use the detail present in many exemplars of ending it in -ium. However, they also followed the more abstract principles that went beyond the recombination of existing exemplars, including having their construction include four syllables and contain a noun, often a proper noun, as a root (e.g., dukinium, kryptonium). In contrast, names for a new laundry detergent did not contain any obvious combinations of details of existing products. Instead the undergraduates relied on general principles: the name had one or two syllables and contained a common noun related to cleanliness, often misspelled (e.g., brite, kleen, sparkle). The schemata followed the detailed and abstract properties of exemplars that other undergraduates recalled (Rubin et al., 1991). Similar constructions using general principles held for coins and ballads (Rubin \& Kontis, 1983; Rubin et al., 1993). Thus, concepts more abstract that particular instances are common for emotionally neutral domains. For emotional domains, similar effects of abstracting and using emotions independent of the instances would be consistent with these findings, schema theory, and the role of emotions in shaping general reactions to past and future events. Note that no fundamental difference is made here, or in Bartlett's theory, of differences in construction between what could be labeled semantic and episodic memory. For both individual instances and organized schemata exist, for both the process of construction is similar, and for both schemata dominate the construction.

The results of the examples just given and the role of explanation-based learning emphasize the role of more abstract principles over details in schema-guided construction and reconstruction. This too was Bartlett's view. In summarizing his chapter "A Theory of Remembering," Bartlett (1932, p. 213) noted, "Remembering is not the re-excitation of innumerable fixed, lifeless and fragmentary traces. It is an imaginative reconstruction, or construction, built out of the relation of our attitude towards a whole active mass of organised past reactions or experience, and to a little outstanding detail." He went on to explain that the details, which would be consistent with the recombined details of the constructive episodic simulation hypothesis (Schacter \& Addis, 2007, 2009), are not the causal factor in determining the search for an existing memory. "Some of the items of a mass may stand out by virtue of their possession of certain physical characteristics. But there is no evidence that these can operate in determining a specific reaction, except after relatively short periods of delay" (Bartlett, 1932, pp. 213-214).

\section{Experiments and Predictions}

Here, I investigate the construction of future events that involve autonoetic consciousness or reliving - that is, episodic future thought. I intend to demonstrate that a great deal can be gained by making fuller use of schema theory and of the extensive findings on the ratings of the basic systems needed to construct memories of past events. To do this, I conducted three experiments to produce results that extend and that contrast the existing views of future episodic thought to those that follow from knowledge of 
schema theory and of the construction of autobiographical memories. Most of the existing studies have asked for events in general rather than for specifically negative events, and those studies have shown a greater positivity bias in the future than in the past. Here, in the first experiment, I asked for future and past, as well as positive and negative events, as did D'Argembeau and Van der Linden (2004). To enhance any effects I also asked for events that would have a great impact on the participants. The existing future episodic thought literature and schema theory have clearly different predictions. The future episodic thought literature, based on its findings and reviews of general psychology (e.g., Szpunar, 2010), expects future events to be more positive. In contrast, schema theory would expect the valence of future events to be more extreme than past events for whichever valence is requested, because one should get a clearer view of the schema for such extreme events less hampered by the reality of the past. Moreover, there are many culturally common schemata for many types of positive and negative events, and these should come into play. Thus, both the standard literature on future episodic thought and schema theory predict greater positivity for the future positive events. The differential prediction is for negative events. For these, there is the advantage of added standardized measures of reactions to these events from the PTSD literature that probe the participants' reactions in a more detailed fashion than do simple valence or intensity ratings of the memories themselves.

In the second experiment, to further understand the claim that future imagined events are less detailed and require more effort, I had participants construct and rate future events, then describe details of these events, and finally rate their properties again. With effort, novelists as well as less skilled writers can produce detailed future events. Here, by increasing the effort expended in producing details in these extra steps, the trade-off between effort and the rated properties of details used in the future episodic thought literature can be directly examined. In doing so, I also ask if the expected lack of rated vividness on the first construction of the future negative events is mirrored in the ratings of activity in all systems involved in constructing the memories or only a subset of systems. Because participants were asked for negative events that strongly affected them, there are expectations from the existing PTSD literature on autobiographical memory for traumatic events. For this experiment, I also have contrasting predictions from future episodic thought and schema theory. As reviewed, the future episodic thought literature, especially the constructive episodic simulation hypothesis, emphasizes details. In contrast, schema theory emphasizes general principles, as the contrasting of explanation- and similarity-based learning and the quote from Bartlett both show. Thus, according to the future episodic thought literature, increasing details should have a major effect on many of the properties of memories in addition to those directly related to increased details, such as visual, auditory, and spatial vividness. In contrast, adding details should have a minor effect on these other properties according to schema theory.

In both experiments, to evaluate and demonstrate the advantages of integrating over various literatures, I add standard theory and measures from autobiographical memory research not commonly used in current research on future thought. In particular, I make use of theoretically motivated, well-studied measures of the basic systems that contribute to autobiographical memory recall, measures whose behavioral properties, stability, and in most cases neural basis are known. Moreover, I measure the metacognitive judgment of the sense of reliving of memories, a key factor in Tulving's concepts of autonoetic consciousness and mental time travel, to examine if reliving is predicted by the same basic systems as are past memories.

In Experiments 1 and 2, no attempt was made to counterbalance past and future events. This is because past events from the same category as the future events could easily serve as highly available instances that could prove to be easier routes to constructing a future event than actually constructing one from general knowledge. For completeness, in Experiment 3, I check that this did not distort the results by using a between-subjects design in which the past event is generated first by half the participants.

\section{Experiment 1}

\section{Method}

Participants. Seventy-six Duke University undergraduates (46 female, mean age $=19.02$ years, $S D=1.06$, range $=18-23$ years) completed the experiment.

\section{Materials.}

Autobiographical Memory Questionnaire (AMQ). The AMQ (Rubin, Boals, \& Berntsen, 2008; Rubin et al., 2003, 2004, 2011; Rubin \& Siegler, 2004) as used here is shown in Table 1. This set of rating scales is intended to measure the basic processes used in constructing autobiographical memory, reliving, and properties of the memories. Items were selected for their relevance to this study, and minor changes made in tense were made when the items were applied to future events.

Centrality of Event Scale (CES). The CES (Berntsen \& Rubin, 2006, 2007) measures the extent to which a traumatic memory forms a central component of personal identity, a turning point in the life story, and a reference point for everyday inferences. The short form of the CES, which was used, consists of seven items rated in relation to the most stressful or traumatic event in the person's life.

Closure. The Closure Scale measures the extent to which individuals believe they have attained psychological closure and resolution surrounding a negative experience. It is an important component of individuals' narrative of a negative event and its impact. Memories that lack closure have high levels of intense negative emotional details (Beike \& Wirth-Beaumont, 2005), are more likely to involve attempts at meaning making (Boals, Banks, Hathaway, \& Schuettler, 2011), and are involved in the ability of autobiographical memories to influence behavior (Beike, Adams, \& Naufel, 2010).

Neuroticism (N). N comes from the Big Five Inventory (BFI; John, Donahue, \& Kentle, 1991), which is a 44-item measure of the broad personality domains of extraversion, neuroticism, agreeableness, conscientiousness, and openness. $\mathrm{N}$ is assessed by eight short phrases. The reliability convergent and discriminant validity of the scales are well established (John \& Srivastava, 1999).

PTSD Checklist (PCL). The PCL (Blanchard, JonesAlexander, Buckley, \& Foneris, 1996; Weathers, Litz, Huska, \& Keane, 1994) has participants nominate a specific stressful event and rate it on 5-point scales from not at all to extremely how much they have been bothered by it on each of 17 symptoms of PTSD identified in the Diagnostic Statistical Manual of Mental Disor- 
Table 1

Autobiographical Memory Questionnaire $(A M Q)$ Variables

\begin{tabular}{ll}
\hline Variable & \multicolumn{1}{c}{ Brief description of rating scales } \\
\hline $\begin{array}{l}\text { Reliving } \\
\text { Intensity }\end{array}$ & While remembering the event, I feel as though I am reliving the event. \\
Reaction & While remembering, the emotions that I feel are intense. \\
& While remembering the event, I have a physical reaction (I felt tense, sweaty, felt \\
cramps or butterflies in my stomach, my heart pounded, etc.). \\
Valence & While remembering, the emotions are negative or positive. \\
See & While remembering the event, I can see it in my mind. \\
Setting & While remembering the event, I know the setting. \\
Hear & While remembering the event, I can hear it in my mind. \\
In Words & While remembering the event, it comes to me in words. \\
Story & It comes to me in words or in pictures as a coherent story. \\
Thought & In the time since the event, I have thought about it. \\
Talked & In the time since the event, I have talked about it. \\
Involuntary & In the time since the event, the memory has come to me "out of the blue," without my \\
& trying to think about it. \\
\hline
\end{tabular}

Note. Valence was rated from -3 ("extremely negative") to 3 ("extremely positive"). All other items were a scale from 1 to 7 . They were anchored at "not at all" and either "as if it were happening now" or "extremely strongly" for reaction; at "completely" for story; or at "all the time" for thought, talked, and involuntary.

ders (DSM-IV-TR; American Psychiatric Association, 2000), such as repeated, disturbing memories, thoughts, or images of the stressful experience; feeling very upset when something reminded you of the stressful experience; avoiding activities or situations because they reminded you of the stressful experience; and being "superalert" or watchful or on guard.

Severity. I used a five-item scale of the severity of an event that combined measures of four specific kinds of loss and one overall judgment (Rubin \& Feeling, in press). For each event, participants rated the following five items on the same 7-point scale:

1. How much physical damage did the event do to you or others very close to you?

2. How much emotional damage did the event do to you or others very close to you?

3. How much financial damage did the event do to you or others very close to you?

4. Overall, how much does this event affect your future?

5. Overall, I believe that if the event happened to most people, they would consider the severity of the event as: $1=$ negligible to $7=$ as much as any event I could imagine.

Procedure. Participants completed a web-based testing at the beginning of each semester that is used to screen students for later experiments in the Department of Psychology and Neuroscience. It included the PCL and CES about the participant's most troubling and stressful past event and our measure of $\mathrm{N}$. The interval between that testing and the current study was a minimum of one week.

In the laboratory, all participants did the same tasks in the same order for five sets of events; each set consisted of three events. The first set consisted of neutral events from the past, and the remaining four sets comprised a two (past/future) by two (positive/negative) design. The three neutral events were intended to instruct and famil- iarize the participants on the task and help anchor their responses. Participants were asked to recall and briefly describe: "1) an event that occurred in a class you attended within the last year, 2) a phone call that occurred within the last year, and 3) a meal with family or friends within the last year." They were then asked to imagine the three negative events "that might occur within the next year that would impact you a lot," to remember the three negative events that "occurred within the last year that impact you a lot," to imagine the three positive events "that might occur within the next year that would impact you a lot," and to remember the three positive events that "occurred within the last year that impact you a lot." The order was chosen to prevent the past events selected from determining the future events and to end the experiment with six positive events to avoid a negative mood induction. For all 15 events, participants completed the version of the AMQ shown in Table 1. Immediately after the AMQ for the third negative future event, the participants completed the PCL, Closure Scale, and CES once as if all three events had actually occurred. They completed the same instruments again once for the combined three past negative events after the AMQ for the third negative past event. The standard instructions for these instruments were prefaced by "imagine that it is a month or more after the three negative events that you just imagined ... indicate how much you would have been impacted." The month delay from the events is required by the PTSD diagnosis. The tests were administered for the combined future and combined past events instead of after each event to have the participants indicate the cumulative effects of the future and past events and to avoid the potential decrease in motivation of completing six instead of two versions of the same tests.

\section{Results}

Differences in the reactions to past and future events. Table 2 includes the means and analyses of variance (ANOVAs) for the PCL, CES, Closure, and Severity for the three negative future events combined and three past negative events combined. The PCL, CES, Closure, and Severity scales were designed for past events, but the concepts they probe and their items apply equally well to imagined future events. As shown in Table 2, the 
Table 2

Means of Instruments Measuring Properties of Negative Events From Experiments 1 and 2

\begin{tabular}{|c|c|c|c|c|c|c|c|c|c|c|}
\hline \multirow[b]{2}{*}{ Measure } & \multirow[b]{2}{*}{ Experiment } & \multirow[b]{2}{*}{ Comparison } & \multicolumn{3}{|c|}{ Past events } & \multicolumn{3}{|c|}{ Future events } & \multicolumn{2}{|c|}{ ANOVAs } \\
\hline & & & $M$ & $S D$ & $\alpha$ & $M$ & $S D$ & $\alpha$ & $F\left(1, d f^{a}\right)$ & $\eta^{2}$ \\
\hline \multirow[t]{4}{*}{ PCL } & Experiment 1 & Past/Future 1 & 36.51 & 13.17 & .92 & 52.80 & 12.68 & .90 & $96.44^{* * * * *}$ & .44 \\
\hline & Experiment 2 & Past/Future 1 & 37.67 & 16.56 & .96 & 53.68 & 13.99 & .91 & $54.16^{* * * * *}$ & .47 \\
\hline & Experiment 2 & Past/Future 2 & & & & 54.03 & 15.73 & .94 & $65.22^{* * * * * *}$ & .51 \\
\hline & Experiment 2 & Future 1/Future 2 & & & & & & & 0.12 & .00 \\
\hline \multirow[t]{4}{*}{ CES } & Experiment 1 & Past/Future 1 & 2.76 & 1.12 & .92 & 3.16 & 0.84 & .82 & $9.88^{* *}$ & .11 \\
\hline & Experiment 2 & Past/Future 1 & 2.67 & 1.07 & .93 & 3.33 & 0.94 & .91 & $19.68^{* * * * *}$ & .24 \\
\hline & Experiment 2 & Past/Future 2 & & & & 3.36 & 0.98 & .93 & $19.55^{* * * * *}$ & .24 \\
\hline & Experiment 2 & Future 1/Future 2 & & & & & & & 0.18 & .00 \\
\hline \multirow[t]{4}{*}{ Closure } & Experiment 1 & Past/Future 1 & 4.02 & 1.77 & .81 & 3.25 & 1.47 & .77 & $11.34^{* * *}$ & .13 \\
\hline & Experiment 2 & Past/Future 1 & 4.35 & 2.28 & .89 & 3.08 & 1.65 & .83 & $13.32^{* * *}$ & .18 \\
\hline & Experiment 2 & Past/Future 2 & & & & 2.88 & 1.67 & .84 & $19.30^{* * * * * *}$ & .24 \\
\hline & Experiment 2 & Future 1/Future 2 & & & & & & & 2.34 & .04 \\
\hline \multirow[t]{4}{*}{ Severity } & Experiment 1 & Past/Future 1 & 3.49 & 1.18 & .64 & 4.06 & 1.28 & .74 & $13.81^{* * * *}$ & .16 \\
\hline & Experiment 2 & Past/Future 1 & 3.11 & 1.20 & .78 & 3.92 & 1.15 & .76 & $23.87^{* * * * * *}$ & .28 \\
\hline & Experiment 2 & Past/Future 2 & & & & 4.12 & 1.09 & .71 & $36.18^{* * * * *}$ & .37 \\
\hline & Experiment 2 & Future 1/Future 2 & & & & & & & $6.51^{*}$ & .10 \\
\hline
\end{tabular}

Note. ANOVAs $=$ analyses of variance; $d f=$ degrees of freedom; PCL $=$ PTSD Checklist CES $=$ Centrality of Event Scale.

${ }^{\mathrm{a}}$ For Experiment $1, d f=75$; for Experiment $2, d f=62$.

${ }^{*} p<.05$. ** $p<.01$. **** $p<.001$. ***** $p<.0001$.

scales produced high and equal reliabilities, as measured by Cronbach's alpha, for both the past and future events. The future events were rated as more troubling than the past events as indicated by their higher PCL, CES, and Severity scores and their lower Closure score. The effects of past versus future on the PCL are dramatic, going from a fairly common level for undergraduates to one that is beyond a standard cutoff of 44 for PTSD if the events were real traumas (Blanchard et al., 1996). As concrete contrasts, the values in Table 2 for the PCL scores for same participants for the "negative event or experience from your life that is most troubling and stressful to you now" taken in the web-based testing earlier in the semester $(M=28.55, S D=10.37)$ were similar to the average of the three events from last year, demonstrating that the events generated produced reactions in line with the participant's most stressful event. The future levels of the PCL are comparable to those obtained in autobiographical memory study with a community-dwelling sample of 75 adults with a clinical diagnosis of current PTSD (for details, see Rubin et al., 2011). The traumas on which these participants were diagnosed were categorized as a life-threatening illness, accident, or witnessing a death $(33 \%)$; adult violence or sexual assault $(30 \%)$; child violence or sexual assault (19\%); combat (11\%); and other trauma (7\%). Their PCL scores $(M=49.10, S D=15.69)$ were about the same as the average of the future three events that might occur in the undergraduates' next year. Thus, the expected reactions to future worst events were not only greater than the actual reactions to past worst events; they would clearly be in the clinical range of responses.

The tendency to see greater effects of future events just noted might be viewed as a general personality trait of neuroticism, which could lead to worry, catastrophizing, and increased expected levels of PTSD symptoms. However, here it was demonstrated as a general effect averaging over all participants. There is a neuroticism score, as well as a PCL for the participant's most stressful life event, from the general screening done at the beginning of the semester. The correlation between neuroticism and the PCL from the general screening was $.48(d f=75, p<.0001)$, demonstrating a standard result in PTSD research (Rubin, Berntsen, \& Bohni, 2008). The correlation of this neuroticism score and the PCL for the past negative events from Experiment 1 is $.29(p<.05)$, but for the future events the correlation is not significant, $r(75)=-.03$. This demonstrates that the increased PCL score appears to hold equally for all participants independent of their level of neuroticism, rather than being caused mainly by those participants who scored highly in neuroticism. This result is consistent with the view that requests for negative future events lead to constructions guided by culturally shared schemata and that these "worst case" constructions are evaluated as equally troublesome by people, independent of neuroticism.

Correlations between AMQ measures on past and future events as indicators of common processing. In this section, I examine in a direct, quantitative manner the extent to which participants report using processes involved in constructing events to the same extent for both past and future events. The AMQ used here to do this has 12 measures. Because the pattern of result is of interest, I report significance at a minimum of $p<.05$; however, to minimize the chances of drawing conclusions from results that would not meet experiment-wide significance, I adopt a Bonferroni correction (i.e., .05/12 $=.004$ ) for examining individual items. Where there are three comparisons for each of the 12 measures the Bonferroni correction would be $p<.001$, a $p$ level that is reported in the tables. The first two columns of Table 3 contain the reliabilities of the past and future ratings. Their geometric mean is the maximum correlation to be expected, given these reliabilities. These reliabilities and the correlations in correlations in the third column are based on six events, the three positive and the three negative events, in order to increase the reliabilities of the measures and because there were no clear differences in the reliabilities and correlations except for valence. For the experimentally manipulated measure of valence, averaging 
Table 3

Reliabilities of and Correlations Between AMQ Ratings From Experiments 1 and 2

\begin{tabular}{|c|c|c|c|c|c|c|c|c|c|}
\hline \multirow[b]{3}{*}{ Measure } & \multicolumn{3}{|c|}{ Experiment 1} & \multicolumn{6}{|c|}{ Experiment 2} \\
\hline & \multicolumn{2}{|c|}{ Alphas } & \multirow{2}{*}{$\frac{r(74)}{\text { Past/Future }}$} & \multicolumn{3}{|c|}{ Alphas } & \multicolumn{3}{|c|}{$r(61)$} \\
\hline & Past & Future & & Past & Future 1 & Future 2 & Past/Future 1 & Past/Future 2 & Future 1/Future 2 \\
\hline Reliving & .74 & .86 & $.52^{* * * * *}$ & .77 & .57 & .77 & $.54^{* * * * * *}$ & $.54^{* * * * *}$ & $.51^{* * * * * *}$ \\
\hline Intensity & .67 & .85 & $.67^{* * * * * *}$ & .71 & .54 & .74 & $.61^{* * * * * * *}$ & $.47^{* * * * * *}$ & $.55^{* * * * *}$ \\
\hline Reaction & .63 & .85 & $.85^{* * * * * *}$ & .68 & .58 & .78 & $.56^{* * * * * *}$ & $.65^{* * * * * *}$ & $.61^{* * * * * * *}$ \\
\hline Valence & .02 & .29 & .14 & .54 & .55 & .39 & $.32^{*}$ & $.30^{*}$ & $.51^{* * * * * *}$ \\
\hline See & .55 & .82 & $.48^{* * * * *}$ & .62 & .19 & .70 & $.46^{* * * *}$ & $.47^{* * * * * *}$ & $.49^{* * * * *}$ \\
\hline Setting & .61 & .80 & .16 & .38 & .48 & .71 & .11 & $.30^{*}$ & $.63^{* * * * * *}$ \\
\hline Hear & .61 & .78 & $.67^{* * * * *}$ & .58 & .58 & .79 & $.50^{* * * * *}$ & $.48^{* * * * * *}$ & $.72^{* * * * *}$ \\
\hline In words & .73 & .83 & $.60^{* * * * *}$ & .82 & .69 & .81 & $.52^{* * * * * *}$ & $.48^{* * * * * *}$ & $.66^{* * * * * *}$ \\
\hline Story & .65 & .78 & $.48^{* * * *}$ & .74 & .40 & .56 & $.36^{* * \dagger}$ & $.36^{* * \dagger}$ & $.57^{* * * * * *}$ \\
\hline Thought & .53 & .62 & $.48^{* * * *}$ & .64 & .09 & .47 & $.44^{* * * *}$ & $.45^{* * * *}$ & $.65^{* * * * *}$ \\
\hline Talked & .56 & .74 & $.54^{* * * * *}$ & .54 & .38 & .64 & $.51^{* * * * * *}$ & $.55^{* * * * * *}$ & $.68^{* * * * * *}$ \\
\hline Involuntary & .69 & .78 & $.66^{* * * * * *}$ & .69 & .61 & .62 & $.30^{*}$ & $.37^{* * * \dagger}$ & $.65^{* * * * * * *}$ \\
\hline
\end{tabular}

Note. For Experiment 1, the correlation of past and future are for the three negative and three positive events combined. For Experiment 2, only negative events were used, as no negative future events were available.

${ }^{*} p<.05 .^{* *} p<.01 .^{* * \dagger} p<.004$ (.05 Bonferroni correction). ${ }^{* * * *} p<.001 .{ }^{* * * * *} p<.0001$.

over positive and negative events reduces the reliabilities and correlations.

As shown in the third column of Table 3, there are substantial correlations between the ratings of past and future events among all measures except for valence and setting. The correlations between the way participants rated their past and future memories measure the extent to which individuals indicate experiencing the concepts underlying each measure (e.g., reliving, emotional intensity and valence, visual imagery) and by inference the degree to which these processes were active. The substantial correlations therefore suggest that the processes used to construct the memories were similar. That is, individuals whose ratings on a measure were higher or lower than those of other individuals for past events were also higher or lower on that measure for future events. Moreover, the correlations indicated that for some measures these relations were often as strong as they could be, given the reliabilities. Given the evidence that information obtained while a cognitive task is ongoing generally provides valid prediction (Ericsson \& Simon, 1993) and the neural data reviewed earlier, this supports, for the first time in a direct quantitative fashion, the claim that individuals use the same processes to similar degrees in constructing past and future events. The alternative is that such usually predictive measures when aggregated over many memories and different tasks no longer measure underlying processes.

Mean differences in the AMQ. Unlike the PCL and other measures shown in Table 2, which report reactions to past and future events, direct measures of memory and future episodic thought are presented in Table 4. The means and ANOVAs of Table 4 provide several interesting conclusions. First, the means for the AMQ variables in all four conditions, except for valence, which was explicitly manipulated, were generally in the middle of their 1 to 7 range and consistent with other studies (e.g., Rubin et al., 2003). Thus, the participants were able to remember and imagine events in a way that produced a reasonable distribution of

Table 4

Means and ANOVAs for Past and Future Events for the AMQ Ratings From Experiment 1

\begin{tabular}{|c|c|c|c|c|c|c|c|c|c|c|c|c|c|c|}
\hline \multirow[b]{3}{*}{ Measure } & \multicolumn{4}{|c|}{ Past } & \multicolumn{4}{|c|}{ Future } & \multicolumn{6}{|c|}{ ANOVA } \\
\hline & \multicolumn{2}{|c|}{ Positive } & \multicolumn{2}{|c|}{ Negative } & \multicolumn{2}{|c|}{ Positive } & \multicolumn{2}{|c|}{ Negative } & \multicolumn{2}{|c|}{ Valence } & \multicolumn{2}{|c|}{ Past/Future } & \multicolumn{2}{|c|}{ Interaction } \\
\hline & $M$ & $S D$ & $M$ & $S D$ & $M$ & $S D$ & $M$ & $S D$ & $F(1,75)$ & $\eta^{2}$ & $F(1,75)$ & $\eta^{2}$ & $F(1,75)$ & $\eta^{2}$ \\
\hline Reliving & 4.77 & 1.37 & 4.47 & 1.37 & 3.92 & 1.57 & 3.81 & 1.42 & 3.22 & .01 & $27.31^{* * * * * * *}$ & .15 & 1.10 & .00 \\
\hline Intensity & 4.69 & 1.39 & 4.63 & 1.17 & 4.14 & 1.49 & 5.00 & 1.33 & $13.14^{* * * * *}$ & .06 & 0.62 & .00 & $36.90^{* * * * * *}$ & .08 \\
\hline Reaction & 2.88 & 1.49 & 3.11 & 1.49 & 2.91 & 1.62 & 3.41 & 1.55 & $8.82^{* * *}$ & .05 & 3.67 & .01 & 1.46 & .01 \\
\hline Valence & 2.04 & 0.78 & -1.93 & 0.79 & 1.95 & 0.94 & -2.02 & 0.89 & $853.35^{* * * * *}$ & .87 & 1.30 & .00 & 0.00 & .00 \\
\hline See & 5.20 & 1.14 & 4.79 & 1.11 & 4.32 & 1.48 & 3.97 & 1.39 & $11.22^{* * * \dagger}$ & .04 & $40.13^{* * * * * *}$ & .19 & 0.11 & .00 \\
\hline Setting & 5.55 & 1.10 & 5.28 & 1.14 & 3.49 & 1.63 & 2.89 & 1.56 & $15.56^{* * * * *}$ & .02 & $150.16^{* * * * * *}$ & .53 & 2.77 & .00 \\
\hline Hear & 4.21 & 1.46 & 4.06 & 1.35 & 3.25 & 1.48 & 3.22 & 1.44 & 0.54 & .00 & $61.87^{* * * * *}$ & .21 & 0.30 & .00 \\
\hline In words & 4.05 & 1.58 & 4.05 & 1.44 & 3.26 & 1.55 & 2.99 & 1.38 & 1.52 & .00 & $42.97^{* * * * * *}$ & .22 & 2.41 & .00 \\
\hline Story & 4.71 & 1.28 & 4.40 & 1.37 & 3.70 & 1.54 & 3.51 & 1.39 & $4.61^{*}$ & .01 & $45.08^{* * * * * * *}$ & .20 & 0.26 & .00 \\
\hline Thought & 4.74 & 1.30 & 4.93 & 1.09 & 5.32 & 1.05 & 4.86 & 1.22 & 1.59 & .01 & $5.04^{*}$ & .02 & $9.98^{* * * \dagger}$ & .04 \\
\hline Talked & 4.36 & 1.36 & 4.19 & 1.28 & 4.51 & 1.52 & 3.89 & 1.46 & $9.27^{* * * \dagger}$ & .04 & 0.32 & .00 & $4.07^{*}$ & .01 \\
\hline Involuntary & 3.16 & 1.45 & 3.63 & 1.44 & 3.48 & 1.60 & 3.72 & 1.43 & $7.23^{* *}$ & .03 & 2.97 & .01 & 0.97 & .00 \\
\hline
\end{tabular}

Note. $\mathrm{ANOVAs}=$ analyses of variance; $\mathrm{AMQ}=$ Autobiographical Memory Questionnaire.

$* p<.05 .{ }^{* *} p<.01 .{ }^{* * *} p<.004$ (.05 Bonferroni correction). ${ }^{* * * *} p<.001 .{ }^{* * * * *} p<.0001$. 
phenomenological reports. Second, the effects of the positive versus negative valence were as expected. Negative events produced more intensity, as is often the case (e.g., Berntsen \& Bohn, 2010), here especially in the future. Positive events produced more of the sensory variables of see and setting (Fredrickson, 2001; Fredrickson \& Branigan, 2005; Talarico, Berntsen, \& Rubin, 2009).

Third, the future/past manipulation had clear effects on some variables and minimal effects on others. In particular, for future events the sensory measures of see, hear, and setting, the language and narrative coherence measures of in words and story, and the sense of reliving, which usually correlates with the sensory variables (e.g., Rubin et al., 2003), were all much lower, with mean difference on the order of one unit on a 7-point scale and effect sizes between 15 and $53 \%$ of the total variance. Given the higher levels of the PCL, CES, and Severity scores and the lower Closure score for future events, the direction of these effects is counter to what would be expected. In contrast, there were no significant differences, even at the .05 level, in the emotional measures of intensity, reaction, and valence and the availability measures of thought, talked, and involuntary, with effect sizes between 0 and $3 \%$. It is as if all the AMQ ratings were lower than would be expected for future events, with an increase in ratings directly related to PTSD symptoms of the increased arousal and availability of traumatic events offsetting the difference and producing no effect. These results replicate D'Argembeau and Van der Linden (2006) for the measures not involving emotion, which were directly manipulated here.

Multiple regressions predicting reliving. As a further investigation of the similarity of processing, in Table 5, measures that predicted the metacognitive judgment of reliving that is often used to separate episodic memories from knowledge (Tulving, 1972) were examined as in previous studies (e.g., Rubin, Schrauf, \& Greenberg, 2003; Rubin \& Siegler, 2004). To ensure that the predictions of reliving of past events would generalize, I reanalyzed the data of participants who had rated the same measures and who were drawn from the same population as the current study, though for the goals of that study had an oversampling of individuals who scored high on the PCL. They provided four types of autobiographical memories: 15 word-cued, "the seven most important events in your life," "the three most positive events in your life," and "the three most negatively stressful or traumatic in your life" (Rubin, Boals, \& Berntsen, 2008, pp. 596-597). The three most negative events are like those of Experiment 1, except that they are not restricted to the most recent year. For the published study and Experiment 1, the regressions from the different conditions are extremely regular, with one of the two measures of emotional intensity (intensity or reaction) and at least one of the two measures of visual-spatial clarity (see or setting) entering in all equations. For all the past, but not the future memories, the measure of narrative coherence (story) also entered. That is, the same AMQ measures have similar correlations with reliving when the effects of other AMQ measures are simultaneously entered into a statistical prediction, with one clear repeated difference in narrative coherence between the past and future regressions. Such replications again add confidence to these findings.

Contents of the future events as evidence for and descriptions of schemata. The contents of the negative future thought can be examined to see if common categories exist that could support general abstract schemata. Two undergraduate coders and the author read the descriptions and arrived at categories. For the more common categories, a second, more detailed level of categories was also created. The coders sorted descriptions into categories independently, and the categories were revised to remove ambiguities that allowed descriptions to be placed in different categories. After this process, $6 \%$ of the descriptions were classified differently by the coders, with the author making the final classification. Events that did not easily form categories involving four or more responses are not reported; there were 34 such events, accounting for $15 \%$ of the total number of responses. Following each category is the percent of participants reporting it. In two cases a participant reported two events in the same category, only one of which was included in the percentages of participants reporting each category that follows.

Academic problems were reported by $58 \%$ of the participants, including having overall lower grades than expected or needed for current plans (25\%), failing a class or exam (15\%), and having lower grades in a class $(9 \%)$ or an exam (10\%). Death and illness

Table 5

Multiple Regressions for the Dependent Variable Reliving From Experiments 1 and 2

\begin{tabular}{|c|c|c|c|c|c|c|c|c|c|c|c|}
\hline \multirow[b]{2}{*}{ Experiment } & \multirow[b]{2}{*}{ Future/Past } & \multirow[b]{2}{*}{ Type of memory } & \multicolumn{8}{|c|}{ Beta weights for independent variable } & \multirow[b]{2}{*}{$R^{2}$} \\
\hline & & & Intensity & Reaction & Valence & See & Setting & Hear & Story & Thought & \\
\hline Rubin et al. (2008) & Past & Word cued & .30 & & & .46 & & & .25 & & .55 \\
\hline Rubin et al. (2008) & Past & Important & .20 & & & .44 & & & .20 & & .39 \\
\hline Rubin et al. (2008) & Past & Positive & & .16 & & & .49 & & .24 & & .43 \\
\hline Rubin et al. (2008) & Past & Negative & .21 & & & .47 & & & .20 & & .49 \\
\hline Experiment 1 & Past & Positive & .66 & & & & .30 & & & & .72 \\
\hline Experiment 1 & Past & Negative & .56 & & .19 & .34 & & & .19 & & .72 \\
\hline Experiment 2 & Past & Positive & .55 & & & .35 & & & & .15 & .73 \\
\hline Experiment 2 & Past & Negative & .39 & & & .53 & & & & & .69 \\
\hline Experiment 1 & Future & Positive & .63 & . & & & .16 & .20 & & & .74 \\
\hline Experiment 1 & Future & Negative & .34 & & & .63 & & & & & .74 \\
\hline Experiment 2 & Future1 & Negative & .55 & & & .23 & & & & & .48 \\
\hline Experiment 2 & Future2 & Negative & .27 & & & .60 & & & & & .59 \\
\hline
\end{tabular}

Note. The first four rows are from Rubin, Boals, and Berntsen (2008). Standardized beta weights are shown for all variables that entered the regression with the restriction that they were significantly different from 0 at the .05 level. 
were also common categories. The death of a family member or friend was reported by $39 \%$ of the participants, their own illness or injury by $20 \%$, and that of a family member or friend by $22 \%$. Other common categories were a rejection for a job, graduate school, scholarship, program, or social group (21\%); the end of a romantic relationship (21\%); the end or disruption of a friendship $(16 \%)$; negative events other than illness or death occurring to family and friends, including the divorce of parents (16\%); an automobile accident involving the participant or of family or friends (11\%); a failure or loss in athletics (11\%); a serious disagreement or otherwise problematic interaction with family or friends (9\%); not finding a job (5\%); and having to drop an activity because of limited time (5\%). Overall, our participants share common concerns about the future; this observation is consistent with culturally shared schemata for negative events.

\section{Discussion}

Individual differences analyses demonstrated substantial correlations between past and future events in ratings of the processes and the resulting products used in constructing events, providing a more direct and quantitative measure of the claim of similarities in processing than existed in the future episodic thought literature. This finding occurred in a theoretically motivated set of measures of processes and in how they combine to predict reliving (or preliving). In more standard experimental terms, in which variability among people is not analyzed but viewed as error variance (Cronbach, 1957), the standard finding of reduced sensory vividness (Berntsen \& Bohn, 2010; Berntsen \& Jacobsen, 2008; D'Argembeau \& Van der Linden, 2004, 2006) is replicated but without accompanying reduced levels of emotion or rehearsalproperties that can be seen as related to the arousal and availability symptoms of PTSD. However, the most striking finding is the extreme scores of future events on standardized tests of reactions to traumas.

\section{Experiment 2}

The main goal in Experiment 2 was to attempt to increase the AMQ ratings that were much lower in future than past memories to see if such an increase would further increase PTSD symptoms severity and other standardized tests of reactions to traumatic events. The theoretical question of interest is whether the details and vividness that are central to current understanding of future episodic thought are crucial to increased expected reactions to the future events or whether these negative reactions are better viewed as resulting from a more abstract construction of the unknown future based on general expectations of events. There are contrasting predictions from the episodic future thought literature, which emphasizes the importance of details and their reassembly to form future episodic thought, and the schema literature, which emphasizes general principles with details having minimal effects.

In past work, the amount of detail has been manipulated by varying the cues, familiarity of the setting, or temporal distance into the future (Berntsen \& Bohn, 2010; D’Argembeau \& Van der Linden, 2004; Szpunar \& McDermott, 2008). Here, to eliminate other explanations possible with these manipulations, which change the event, the same three negative future events were constructed twice, with a request to record details of the plot and setting between the two constructions. Who, what, when, and where questions were used to prompt these details. Because of the time and effort taken by this added description task and the request to recall and rate the same events a second time, the neutral training scenarios of Experiment 1 were eliminated. Instead of memories of any kind, three distinct categories were asked for: events from class, receiving news, and a gathering of family or friends. The time period was extended from 1 year to 3 years to make it easier to find past events in these categories. These changes should make the findings easier to generalize by making the contents of the memories somewhat different from the request for negative memories of any kind used in Experiment 1, and they should make the contents more uniform across participants because the specific scenarios limit the kind of events that can be recalled or imagined. The positive future events, which were not needed for any comparisons and lacked any measures of negative reactions, were eliminated to limit the length of the task.

\section{Method}

Participants. Sixty-three Duke University undergraduates (38 female, mean age $=19.02$ years, $S D=0.98$, range $=18-22$ years) not included in Experiment 1 completed the experiment.

Procedure. The procedure was modeled on that of Experiment 1. Participants completed a web-based testing at the beginning of each semester used to screen students for later experiments in the Department of Psychology and Neuroscience, which included the PCL and CES about the participant's most troubling and stressful past event and the measure of $\mathrm{N}$. The interval between that testing and the laboratory session was a minimum of one week. In the laboratory, all participants did the same tasks in the same order for four sets of three events. First, there was a set of three negative future events that were described and rated. Second, there was a set of questions about each of these three future events to further develop their descriptions. Third, these future negative events were rated again. Fourth, there was a set of past negative events that were described and rated once. Finally, there was a set of past positive events, which served to minimize any negative mood inductions.

Each set of three events consisted of the appropriate variant of the following. (a) A very negative (positive) event that may occur (occurred) in a class you attend (attended) within the next (last) three years that would impact you a lot. (b) A very negative (positive) phone call, text, or letter that may occur (occurred) within the next (last) three years that would impact you a lot. (c) A very negative (positive) meal or other gathering with family or friends that may occur (occurred) within the next (last) three years that would impact you a lot. These categories of events were chosen here (and as neutrally valenced practice items in Experiment 1 ) because they were expected to have common, culturally agreed upon schemata that would allow the easy recall of past events and creation of future events. However, one point of the paper is that it is hard to imagine any class of events that are likely to occur to our participants for which they would not have developed highly structured expectancies. For all 12 events, participants completed the version of the Autobiographical Memory Questionnaire shown in Table 1 with minor changes made to accommodate the future events. Immediately after the AMQ for the third event in each of the three sets of negative events, the participants completed 
the PCL, Closure, and CES once, as if all three events had actually occurred.

After participants completed the first construction and rated each of the three future negative events, they were asked to more fully develop the details and description by thinking of the same negative events that they had imagined and answering the following four wh- questions for each: (1) in one to three sentences, briefly describe who would be present at this event (initials could be used for names, but they had to try to be specific); (2) in one to three sentences, briefly describe what would occur at this event in enough detail to let someone else understand what was going on in terms of action and people's motivation; (3) in one to three sentences, briefly describe when this event would occur, including the season and time of day; and (4) in one to three sentences, briefly describe where this event would occur, including the local social setting and geographic location.

Unlike Experiment 1, this was not a two by two design; rather, it included four one-way comparisons, each with two levels: (a) a comparison of the negative past and initial construction of the negative future events intended to be comparable to Experiment 1; (b) a comparison of initial and second construction of the negative future events to examine changes as details were specified; (c) a comparison of the negative past and second construction of the negative future events to see if difference in mean AMQ ratings was reduced; and (d) a valence comparison for past events. The design was changed to allow detailed examination of how increasing the elaboration of the future events would affect the measures.

\section{Results}

On the average for each of their three negative future events, participants recorded 24.08 words $(S D=12.59)$ for their initial description and for their what, when, where, who, and combined four wh- questions: $36.23(S D=15.84), 12.13(S D=6.88), 11.97$ $(S D=5.68), 15.45(S D=9.17)$, and $75.78(S D=29.48)$ words, respectively. Thus, the four wh- questions produced about twice as much additional description as did the initial request to describe the future negative events.
Differences in the reactions to past and future events. The results obtained in Experiment 2 replicate and extend those of Experiment 1. As shown in Table 2, the future events were again rated as more troubling than the past events and to about the same extent as in Experiment 1, as indicated by the higher PCL, CES, and Severity scores and the lower Closure score. The effects on the PCL are again dramatic, going from a fairly common level for undergraduates to one that is beyond standard cutoffs for PTSD. The PCL scores for the three events that occurred within the last 3 years were similar to the PCL scores for same participants for the "negative event or experience from your life is most troubling and stressful to you now" taken in the earlier study in the semester $(M=29.81, S D=10.19, \alpha=.89)$. This demonstrates that the events generated produced reactions in line with the participant's most stressful event. The scores for the future negative events were again clearly in the clinical range of responses if there were an actual as opposed to imagined event. What is added is that in spite of the large difference between past and future memories on all measures in Table 2, there was little increase in the future measures as a function of the attempts in this experiment to increase the detail of the future memory by having participants record responses to four questions about each event. The only significant effect of increased effort on the constructions of the events was on severity.

The relation of neuroticism and the PCL replicated the findings of Experiment 1. The correlation between these variables measured during a general screening done at the beginning of the semester was $.38(d f=56, p<.01)$. The correlation of neuroticism and the PCL for the three past negative events from Experiment 2 is $.27(d f=56, p<.05)$. In contrast, for the first and second future three events the correlations are .07 and .15 (ns).

Mean differences in the AMQ. Table 6 replicates the general findings shown in Table 4 and demonstrates that the manipulation of having participants think more about the details of the future events succeeded in removing the differences between the past and future events; as shown in the right column of ANOVAs, only two differences remained at the .05 level, and neither met the Bonfer-

Table 6

Means, ANOVA, and Correlation Between Past and Future Events for the AMQ Ratings From Experiment 2

\begin{tabular}{|c|c|c|c|c|c|c|c|c|c|c|c|c|c|c|}
\hline \multirow[b]{3}{*}{ Measure } & \multicolumn{4}{|c|}{ Past } & \multicolumn{4}{|c|}{ Negative } & \multirow{2}{*}{\multicolumn{2}{|c|}{$\begin{array}{c}\text { Future } \\
\text { Negative past } \\
\text { vs. Future } 1\end{array}$}} & \multicolumn{4}{|c|}{ ANOVAs } \\
\hline & \multicolumn{2}{|c|}{ Positive } & \multicolumn{2}{|c|}{ Negative } & \multicolumn{2}{|c|}{ First } & \multicolumn{2}{|c|}{ Second } & & & \multicolumn{2}{|c|}{$\begin{array}{l}\text { Future } 1 \text { vs. } \\
\text { Future } 2\end{array}$} & \multicolumn{2}{|c|}{$\begin{array}{l}\text { Negative past } \\
\text { vs. Future } 2\end{array}$} \\
\hline & $M$ & $S D$ & $M$ & $S D$ & $M$ & $S D$ & $M$ & $S D$ & $F(1,62)$ & $\eta^{2}$ & $F(1,62)$ & $\overline{\eta^{2}}$ & $F(1,62)$ & $\eta^{2}$ \\
\hline Reliving & 4.64 & 1.34 & 4.45 & 1.34 & 3.81 & 1.22 & 4.60 & 1.27 & $16.76^{\text {******* }}$ & .21 & $25.29^{* * * * *}$ & .29 & 0.89 & .01 \\
\hline Intensity & 4.12 & 1.37 & 4.14 & 1.34 & 4.12 & 1.22 & 4.49 & 1.28 & 0.02 & .00 & $6.37^{*}$ & .09 & $4.31^{*}$ & .06 \\
\hline Reaction & 2.79 & 1.47 & 2.90 & 1.44 & 2.92 & 1.25 & 3.16 & 1.48 & 0.01 & .00 & 2.41 & .04 & 2.69 & .04 \\
\hline Valence & 2.06 & 0.81 & -1.85 & 0.75 & -1.95 & 0.76 & -1.93 & 0.72 & 0.82 & .01 & 0.05 & .00 & 0.50 & .01 \\
\hline See & 5.10 & 1.10 & 4.92 & 1.20 & 4.54 & 0.94 & 4.95 & 1.15 & $6.90^{*}$ & .10 & $9.22^{* * * \dagger}$ & .13 & 0.04 & .00 \\
\hline Setting & 5.56 & 1.06 & 5.70 & 0.91 & 4.46 & 1.23 & 5.43 & 1.11 & $46.59^{* * * * * *}$ & .43 & $57.78^{* * * * * * *}$ & .48 & 3.15 & .05 \\
\hline Hear & 4.64 & 1.29 & 4.61 & 1.28 & 4.13 & 1.20 & 4.50 & 1.39 & $9.67^{* * * \dagger}$ & .13 & $9.09^{* *{ }^{\prime}}$ & .13 & 0.46 & .01 \\
\hline In words & 4.25 & 1.53 & 4.38 & 1.51 & 3.69 & 1.28 & 4.29 & 1.38 & $15.38^{\text {**** }}$ & .20 & $18.69^{* * * *}$ & .23 & 0.21 & .00 \\
\hline Story & 4.76 & 1.16 & 4.69 & 1.33 & 4.28 & 1.11 & 4.70 & 1.17 & $5.52^{*}$ & .08 & $10.33^{* * \dagger}$ & .14 & 0.01 & .00 \\
\hline Thought & 4.19 & 1.31 & 4.20 & 1.27 & 4.32 & 0.98 & 4.28 & 1.13 & 0.58 & .01 & 0.14 & .00 & 0.22 & .00 \\
\hline Talked & 3.57 & 1.47 & 3.52 & 1.24 & 3.06 & 1.19 & 3.17 & 1.41 & $8.96^{* * * \dagger}$ & .13 & 0.63 & .00 & $4.90^{*}$ & .07 \\
\hline Involuntary & 2.89 & 1.45 & 3.02 & 1.41 & 3.15 & 1.18 & 3.21 & 1.24 & 0.43 & .01 & 0.21 & .00 & 0.97 & .02 \\
\hline
\end{tabular}

Note. $\quad \mathrm{ANOVAs}=$ analyses of variance $\mathrm{AMQ}=$ Autobiographical Memory Questionnaire

${ }^{*} p<.05 .{ }^{* *} p<.01 .^{* * *} p<.004$ (.05 Bonferroni correction). ${ }^{* * * *} p<.001 .^{* * * * *} p<.0001$. 
roni correction. The ratings comparing past events to the initial future events replicated the findings of Experiment 1, with the sensory measures of see, hear, and setting, the language and narrative coherence measures of in words and story, and the sense of reliving being lower for future events, with mean difference on the order of one unit on a 7-point scale and effect sizes between 13 and $43 \%$ of the total variance. The task of answering questions about the future events produced similar-sized effects on these same variables and mostly only on those variables, but in the opposite direction, as shown in the middle column of ANOVAs. This balance produced the lack of past versus future differences in the last column.

Of special note is that the manipulation, which succeeded in increasing the sensory vividness of the memory, affected the emotional and rehearsal ratings of the memory only to a minor extent. The emotional and rehearsal ratings, which are higher in people with high PTSD symptom severity, were close to equal in the past and initial future memories in both experiments. This result mirrors the lack of increase in the PCL in Table 2. Again, this suggests that the emotional and rehearsal responses are not strongly affected by the detailed sensory image of the memory. The effect of valence of the past events is not shown because there were no significant effects, even at the uncorrected .05 level, except for the manipulation check of valence, $F(1,62)=727.85$, $p<.0001, \eta^{2}=.92$.

Correlations between AMQ measures on past and future events as indicators of common processing. The first three columns of Table 3 under Experiment 2 contain the reliabilities of the past and two future ratings. Their geometric mean is the maximum correlation to be expected. These reliabilities and the correlations in the last three columns are based on the three negative events as opposed to the six events of Experiment 1 and so are somewhat lower but in general show the same pattern of results. The correlations between the way participants rated their past and each of the two future memory ratings measure the extent to which individuals indicate experiencing the concepts underlying each measure to the same degree when recalling past and imagining future events. Shown in the last column of Table 3 are the correlations between the values from ratings of the same three future events rated twice when separated by only a request for more details. In addition, that column provides another reasonable measure of what might be expected as an upper limit for such correlations. The correlations between the past and each of the two future memory ratings for most measures reach these values. As with Experiment 1, valence and setting do not but are much lower. The correlations of story, thought, and talked are a bit lower in Experiment 2 and are similar to their values in Experiment 1. Overall, these correlations suggest that the processes used to construct the past and two future events are generally quite similar.

Multiple regressions predicting reliving. As a further investigation of the similarity of processing shown in Table 3, regressions predicting reliving for the four conditions from Experiment 2 are presented in Table 5. As with the results of Experiment 1 and of an earlier study of past events (Rubin, Boals, \& Berntsen, 2008) shown in Table 5, the regressions from the different conditions are extremely similar; intensity and see entered in all four equations producing $R^{2}$ values in the .5 to .7 range, which approaches the squared reliability of reliving shown in Table 3 . There is no significant contribution of story here. The difference may be because in Experiment 2 specific topics for the events were provided, resulting in the decrease in variability of the story measure as shown in Tables 4 and 6 . Combined, the results provide strong empirical support for the claim of similar levels of involvement of the basic processes used to construct past and future events.

Contents of the future events as evidence for and descriptions of schemata. Two undergraduate coders and the author read the descriptions and arrived at categories for the three kinds of events requested using both the descriptions given initially and the added responses to the who, what, when, and where questions. For the more common categories, a second, more detailed level of categories was also created. The coders sorted descriptions into categories independently, and the categories were revised to remove ambiguities that allowed descriptions to be placed in different categories. After this process, $5 \%$ of the descriptions were classified differently by the coders, with the author making the final classification. Categories involving three (instead of four) or more responses are reported here (as there were fewer participants than in Experiment 1). Following each category is the percent of participants reporting it.

For the class-related event, receiving a low grade (56\%) either by failing a class $(27 \%)$ or an exam $(16 \%)$ or by getting a low grade in the class $(13 \%)$ was the most common category. Being unprepared for or missing a class or exam (21\%) because of a general lack of background (8\%), forgetting or not being aware of an assignment $(6 \%)$, or oversleeping $(6 \%)$ was next. These were followed by being embarrassed in class $(13 \%)$, either by a direct negative evaluation by the professor $(8 \%)$ or by one's own performance $(5 \%)$; a death or illness in class $(5 \%)$; and other responses $(5 \%)$.

For the contents of the phone call, letter, or text, the most common category was the death $(49 \%)$ either of a family member $(43 \%)$ or of the family dog $(6 \%)$; followed by the end of a romantic relationship (17\%); a rejection for a job, graduate school, scholarship, or program $(11 \%)$; illness, injury, or threat to a family member $(10 \%)$; the intended divorce of parents $(5 \%)$; and other responses $(6 \%)$.

For the meal or meeting with family or friends, the most common category was a very unpleasant argument $(51 \%)$ in which the student is a witness not in direct conflict (27\%), is directly involved in a disagreement $(16 \%)$, or is part of a problematic interaction that is not necessarily a disagreement (8\%). Other categories include bad news shared $(17 \%)$ either by others $(11 \%)$ or the student $(6 \%)$, an illness or death at the meeting $(10 \%)$, a gathering in response to a death (10\%), that the student now feels distance from an individual or group he or she was once close to because the student or others have changed $(8 \%)$, and other responses $(5 \%)$.

Thus, for each of the three prompts for negative future events the most common category (e.g., receiving a low grade, being informed of a death, and an argument) accounted for about half of the responses. The second most common category (e.g., being unprepared for a class, being informed of the end of a romantic relationship, and the sharing of bad news) accounted for another fifth. The third and fourth most common categories each accounted for about another tenth, resulting in the top four categories accounting for almost $90 \%$ of the responses. Thus, our participants share common concerns about the future, and many of these 
concerns are well-developed, culturally shared schemata that occur in literature and film.

\section{Discussion}

Experiment 2 generally replicated the findings of Experiment 1 and demonstrated that increasing the sensory vividness of the future negative memories did not affect the PCL, CES, or Closure measures.

\section{Experiment 3}

Experiment 3 was designed to ensure that the key finding of differences between past and future negative events in the PCL and other measures of reactions to traumatic events was not inflated by a repeated-measures design in which future events always came first. To do this, I tested a smaller number of participants in each of two orders of tasks and thus analyzed only the scores on the PCL, Closure, CES, and Severity. In Experiment 1, which compared past and future events, the future events always came first, because recalling future events immediately after past events could emphasize the particular events recalled rather than a general construction; the easiest to generate future events might be strongly affected by the now primed and therefore highly accessible past events just recalled rather than constructions based on the total knowledge base. Here, the order of past and future events was counterbalanced to ensure that order effects did not account for results.

\section{Method}

Participants. Fifty-two Duke University undergraduates (38 female, mean age $=19.23$ years, $S D=1.18$, range $=18-22$ years) completed the experiment.

Procedure. For half the participants, the procedure was identical to that in Experiment 1. For the other half of the participants, the procedure was identical except that they were asked to remember sets of three events before imagining sets of three events. As in Experiment 1, the participants completed the PCL, Closure,
CES, and Severity once after recalling and rating the past and future sets of three negative events. For all participants, as in Experiment 1, the positive events followed the negative events to reduce any negative mood induction.

\section{Results and Discussion}

The analyses for the PCL, CES, Closure, and Severity are a 2 within-subject (past/future) by 2 between-subject (future-past vs. past-future order) ANOVA. The means, standard deviations, reliabilities, and ANOVAs for these measures are shown in Table 7. The past/future means were comparable to those of Experiments 1 and 2, but with fewer participants the past/future $F$ s were smaller, though still significant, indicating that the effects in the earlier experiments were not caused by lack of counterbalancing the order of past and future events. There were no significant effects of order, but interactions for the PCL and Closure were significant. These interactions are consistent with the recall of specific past events influencing the recall of later future events. More important, the expected difference between future and past events in the four measures is seen when they both occur first and thus are not subject to order effects.

\section{General Discussion}

\section{Summary}

Experiments 1 and 2 were similar in form. In Experiment 1, participants were cued for three positive and three negative events of any kind that occurred within the last year or might occur within the next year that would have a strong impact on them. In Experiment 2, they were cued for three negative events that might occur within the next 3 years and three positive and three negative events that occurred within the last 3 years that would have a strong impact on them. The future negative events were rated twice with a request for more details between the two ratings, and three specific kinds of events were cued: an event in a class you attend; a phone call, text, or letter; and a meal or other gathering with

Table 7

Means of Instruments Measuring Properties of Negative Events From Experiment 3

\begin{tabular}{|c|c|c|c|c|c|c|c|c|c|c|c|c|}
\hline \multirow[b]{3}{*}{ Measure } & \multirow{2}{*}{\multicolumn{3}{|c|}{ First task }} & \multirow{2}{*}{\multicolumn{3}{|c|}{ Second task }} & \multicolumn{6}{|c|}{ Past/Future by Order ANOVAs } \\
\hline & & & & & & & \multicolumn{2}{|c|}{ Past/Future } & \multicolumn{2}{|c|}{ Order } & \multicolumn{2}{|c|}{ Interaction } \\
\hline & $M$ & $S D$ & $\alpha$ & $M$ & $S D$ & $\alpha$ & $F$ & $\eta^{2}$ & $F$ & $\eta^{2}$ & $F$ & $\eta^{2}$ \\
\hline \multicolumn{13}{|l|}{ PCL } \\
\hline Past & 35.96 & 9.07 & .82 & 38.00 & 14.60 & .94 & & & & & & \\
\hline Future & 55.31 & 14.85 & .93 & 44.46 & 14.85 & .94 & $38.86^{* * * * *}$ & .13 & 3.93 & .03 & $4.53^{*}$ & .02 \\
\hline \multicolumn{13}{|l|}{ CES } \\
\hline Past & 2.82 & 1.13 & .93 & 2.54 & 0.92 & .90 & & & & & & \\
\hline Future & 3.15 & 1.14 & .74 & 3.10 & 1.01 & .90 & $7.81^{* *}$ & .03 & 0.23 & .00 & 1.05 & .00 \\
\hline \multicolumn{13}{|l|}{ Closure } \\
\hline Past & 3.86 & 2.00 & .85 & 3.51 & 1.92 & .68 & & & & & & \\
\hline Future & 3.55 & 1.87 & .93 & 2.82 & 1.59 & .78 & $4.61^{*}$ & .01 & 0.17 & .00 & $5.34^{*}$ & .01 \\
\hline \multicolumn{13}{|l|}{ Severity } \\
\hline Past & 3.35 & 1.20 & .82 & 3.20 & 1.07 & .91 & & & & & & \\
\hline Future & 3.74 & 1.34 & .80 & 4.16 & 1.41 & .80 & $11.81^{* * * *}$ & .05 & 0.97 & .01 & 0.49 & .00 \\
\hline
\end{tabular}

Note. All $F(1,50)$. ANOVAs $=$ analyses of variance; $\mathrm{PCL}=$ PTSD Checklist $\mathrm{CES}=$ Centrality of Event Scale.

${ }^{*} p<.05 .{ }^{* * *} p<.01 .^{* * * *} p<.001 .^{* * * * *} p<.0001$. 
family or friends. The consistent results over the two experiments and with earlier work indicated the robustness of the findings.

As shown in Table 2, the most striking and novel finding was that future events yielded extremely high means on tests used in the PTSD literature. On the PCL, which is one of the most widely used screening tests for PTSD and one that mirrors closely the official symptoms of the disorder, the set of three future negative events from Experiment 1 and the two sets of three future negative events from Experiment 2 had similar means, which were in the clinical range for this test. Moreover, in comparison to similar past events, the differences were large, with effect sizes accounting for about half of the variance.

Table 3 shows the consistency in how individuals rate the processes and contents of past and future event, providing correlations for a dozen measures that have been highly studied in the autobiographical memory literature, many of which report on basic processes used to construct autobiographical memories (Rubin, 2006, 2012; Rubin et al., 2003). This novel behavioral comparison supports the claim of similar processes in the construction of future and past events in a direct and quantitative fashion. As noted in the introduction, correlations for these measures were about .9 over a 2-week test-retest period when 20 events were rated (Rubin et al., 2004). Here, there was time for only six events in Experiment 1 and three events in Experiment 2, and so the reliabilities and correlations were lower. The correlations of most measures of past and future events were close to their reliabilities. The exceptions were valence and setting. Valence was manipulated by the instructions to be toward the extremes of its scale, and so little can be said about how it would generally correlate. Setting is generally a rating that is much lower in future events and here was quite high in past events, with the result that it had the largest effect size of mean values of any rating outside of valence. Overall, the correlations between the ratings of processes involved in constructing past and future events add support to the claim that individuals vary in the extent to which they use various processes but use them to the same extent in constructing past and future events. The AMQ measures can be seen as indicators of the contents of a memory (e.g., how emotional intense the memory is) or of the process of remembering (e.g., the degree to which emotional processing was involved) depending on whether a reified memory-as-a-thingrecalled metaphor or remembering-as-a-process metaphor is used.

Added support to the claim of stable individual differences in constructing past and future events comes from the prediction of reliving in Table 5. The concept of reliving is central to the idea of mental time travel (e.g., Wheeler et al., 1997) and has been measured in several studies of future episodic thought (e.g., Berntsen \& Bohn, 2010; D'Argembeau \& Van der Linden, 2004; Szpunar \& McDermott, 2008). Here, the extent of reliving (or preliving) was predicted with the measures of Table 1 . As can be seen in Table 5, the predictions are substantial, with $R^{2}$ values in the .48 to .72 range for Experiments 1 and 2. This approaches the maximum expected given the reliability of the reliving measure. Moreover, the same predictors are involved in past and future events here and in earlier work with past events. Intensity (or, in one case from the earlier studies, reaction) and see (or, in three of the four positive past and future events, setting) always enter into the equation. In word-cued memories, see is a better predictor of reliving than setting, but in requests for positive events, setting replaces it. This is consistent with the finding that in positive events, details peripheral to the event are better recalled (Fredrickson, 2001; Talarico et al., 2009). Thus, in addition to replicating the finding that future events are judged to have considerable reliving, I demonstrated the novel finding that the variables that predicted this metacognitive judgment are the same for past and future events.

There were also some replications and novel findings in the means of the 12 AMQ variables as shown in Tables 4 and 6. The ratings comparing past events to the initial future events in Experiments 1 and 2 produce the same results. The sensory measures of see, hear, and setting; the language and narrative coherence measures of in words and story; and the sense of reliving are lower for future events, with mean difference on the order of one unit on a 7-point scale and effect sizes between 13 and $53 \%$ of the total variance. Thus, the lower sensory ratings commonly found were replicated and put into a context of a theoretically motivated battery of measures used to understand the basic processes used to construct autobiographical memories. In this context, little or no past versus future differences were shown by other measures including the intensity, reaction, and valence measures of emotion and the thought, talked, and involuntary measures of availability or rehearsal. In agreement with Van Boven and Ashworth (2007), there was "a slight, but only occasionally significant, tendency for people to expect future emotions to be more intense than they remembered past emotions having been" (p. 289), here especially for negative events. In Experiment 2, the added task of answering questions about the future events eliminated the past versus future differences in ratings. Of special note is that the increase in these measures did not affect the large future versus past differences in the PCL and other tests that vary with PTSD populations.

The lack of neuroticism predicting PTSD symptom severity in future but not past events is a novel finding. It occurs in the context of the high levels of PTSD symptoms in the future. One possibility is that thinking about worst case and otherwise improbable but severe future negative outcomes that result in strong imagined reactions is just part of good planning. Considering future events that might be upsetting may help in trying to avoid them or in tempering reactions if they occur. When requested to imagine future events without specification of valence, people do not normally seem to construct traumatic events. However, this does not imply that extreme imagined reactions to negative future episodic thoughts are in any way dysfunctional. Rather, the finding is consistent with worst case constructions guided by culturally shared schemata being used for planning in a rational fashion. Neuroticism may predict the severity of reactions only when those reactions linger to the extent that they could be considered to be chronic rumination or worry.

As just summarized, where there were overlapping data in the existing literature, this was replicated. In addition, there are instances where the future episodic thought literature and both the autobiographical memory literature and the study of clinical disorders added understanding to each other. Next, the similarity- versus explanation-based learning theoretical distinction from the schema literature is used to understand future episodic thought in general and to further integrate it with clinical theory. 


\section{Similarity- and Explanation-Based Construction of Future Episodic Thought}

A major theoretical advance of future episodic thought is to clarify and stress the constructive nature of memory at both the behavioral and neural levels by showing overall general similarities to future episodic thought, which cannot simply be remembered but must be constructed. In this context, specific differences between past and future constructions can be examined. The differences noted here between less sensory detail and more PTSDrelated reactions in Experiment 1 and the independence of the amount of detail and those reactions in Experiment 2 provide the motivation for the reevaluation of how that construction is done. To do this, I relied on the distinction between similarity-based learning, which is based on the instances that will form the schema, and explanation-based learning, which is more abstract in that it is based on domain knowledge and general principles at a more abstract level rather than particular instances.

The general literature reviewed in the introduction contains the following results that are consistent with the use of explanationbased processes. Future events are typically rated as less detailed than past events, consistent with their being formed from domain knowledge, general principles, or more abstract general schemata rather than from details of instances that are recombined. With more effort, the details can be searched for and added to the event. Consistent with the idea of more schema relevance in the future, future events are rated as more important or personally significant. When no request for events of a specific valence are made, past events are more frequently positive than negative in valence; future events are even more frequently positive, which is consistent with positive schemata for life. Experiments 1 and 2 add the following novel results. The request for negative future events produces reactions that are much stronger than those for the request for negative past events. This is consistent with the implied request to use negative schemata and the lack of constraint that is present, because there are no actual occurrences or particular details that can be used. Moreover, this effect does not depend on, nor is it affected by, reporting vivid details for the event.

\section{Integrating the Future Episodic Thought, Autobiographical, and Clinical Approaches}

Several concrete examples offer suggestions of areas of synergy. I start with a simple example from anxiety disorders (Wenzel, Pinna, \& Rubin, 2004) before noting two broad areas of potential research: PTSD and chronic pain. Anxious individuals bias their processing of threat-related stimuli (Williams, Watts, MacLeod, \& Mathews, 1997), allotting more attention to them and interpreting neutral stimuli as more negative. However, there are differences among anxiety disorders with memory effects being more robust in PTSD and panic disorder than in general anxiety disorder and social phobia. To investigate this difference in disorders using autobiographical memories, Wenzel et al. (2004) used a procedure similar to that used here. Undergraduates recorded three memories for each of five categories, memories of situations in which they experienced trauma, panic, worry, social anxiety, or the positive emotion of being content. For each memory, they provided a brief narrative and ratings on many of the measures used here. Consistent with the clinical literature, there were less well developed memories for the worry and social anxiety situations that are salient for general anxiety disorder and social phobia. In particular, worry and social phobia memories were rated lower than trauma and panic memories and emotionally content memories on sensory variables and two measures of reliving. Raters coded the memory descriptions for whether they explicitly mentioned a negative emotion. Content memories did so $1 \%$ of the time, trauma and panic memories did so $39 \%$ of the time, and worry and social anxiety memories did so $56 \%$ of the time.

One can interpret these differences in terms of the anxiety disorders related to the negative situations, but there is also a future versus past dimension, which had not been well studied in 2004 and which predicts the contrasting direction of the sensory-detail and emotional-reaction effects parallel to the effects found here. In the trauma and panic memories (and in PTSD and panic disorder), negative events have occurred. In the worry and social anxiety memories (and in general anxiety disorder and social phobia), future negative events were expected but did not occur. If the negative events had occurred, the situation would have changed from worry and social anxiety to a reaction to the event itself, which might be sadness, shame, or embarrassment rather than worry or social anxiety. In this way, the anxiety disorder and future/past literature converge and inform each other in a direct fashion that was not as obvious when the Wenzel et al. (2004) study was conducted.

I borrowed heavily from the PTSD literature in Experiments 1 and 2, but PTSD poses something of a contradiction for future episodic thought. As Ehlers and Clark (2000) noted, PTSD is an anxiety disorder and thus should be the result of appraisals of impending threat. However, in PTSD an event has already happened. Ehlers and Clark "suggest that this apparent puzzle can be resolved by proposing that persistent PTSD occurs only if individuals process the traumatic event and/or its sequelae in a way which produces a sense of a serious current threat" (p. 320); that is, in a way that assumes a possible future event. One way to do this is with future episodic thought and with the cognitive representations that are used to construct them.

Several attempts at formulating such representations exist in the clinical literature. One of the earliest is Foa's fear network, in which the associations among stimuli in the environment and emotional and other responses are changed by a traumatic event, so that thoughts about or encounters with those stimuli lead to the expectation of negative outcomes (Foa \& Kozak, 1986; Foa, Steketee, \& Rothbaum, 1989). Exposure to the stimuli in a safe environment is used to attempt to change the associations to include less traumatic associations by providing new, nontraumatic responses to the stimuli. In another influential approach, JanoffBulman (1989) discussed the abstract expectations for the future that people normally have when using a schema framework from social cognition. Traumatic events challenge and change these expectations in measurable ways, resulting in what can be less adaptive behaviors in the future. Therapy attempts to reverse these changes for inappropriate situations. Thus, specific schemata can be identified and their changes measured for individuals.

In addition to trauma, future episodic thought affects chronic pain. Pain catastrophizing is the tendency to focus upon and magnify pain sensations and to feel helpless in the face of pain (Sullivan et al., 2001). It occurs when thinking about a specific actual or anticipated painful experience, and it predicts pain in a 
wide range of situations, including before a painful experience occurs (Keefe, Brown, Wallston, \& Caldwell, 1989). Thus, pain catastrophizing may operate through its ability to affect future episodic thought, and some therapies involve changing those future constructions. In all these examples, quantitative measures exist of the schemata to examine the changes in expectations.

Outside the clinical literature, Berntsen and Rubin (2004) developed the concept of life script based on cognitive studies of emotional autobiographical memory. In operational terms, to measure the life script, participants are asked to list the seven most important events that should occur in a newborn's life. The events tended to be positive, to have a higher density in late childhood and early adulthood, and to have narrow expected age ranges. Negative events are less frequent and when they occur have much broader expected age ranges. Thus, the life script is of a somewhat idealized life with mostly positive events that follow a script with an expected sequence. Life script events appear frequently in future events (Bohn \& Berntsen, 2011), and their proportion increases the further the event is into the future (Berntsen \& Bohn, 2010; Berntsen \& Jacobsen, 2008). However, when a traumatic event occurs that produces PTSD symptoms, that negative event tends to become central to the life story of individuals, as measured by the CES. In people with high levels of PTSD symptom severity, such events can become as central as typical positive life script events (Berntsen, Rubin, \& Siegler, 2011). The CES for the onset of chronic pain predicts actual levels of pain even when other standard predictors have been considered (Perri \& Keefe, 2008). Thus, there exist several independently formulated attempts to examine how expectations about the future affect current symptoms. All could be integrated and measured more easily with the framework of future episodic thought.

\section{Clinical Applications of Similarity- and Explanation- Based Constructions of Future Episodic Thought}

One of the main current approaches guiding research into emotional disorders is the consensus CaR-FA-X model. It has three mechanisms: capture and rumination $(\mathrm{CaR})$, functional avoidance (FA), and impaired executive control (X; Williams et al., 2007). The theory's main concern is the phenomenon of overgeneral memory; that is, the observation that attempts at recalling autobiographical events produce summarized categories of events rather than single episodes. Capture by and rumination about a negative event is of an abstract, explanation-based nature. It lacks details of the event and keeps the search for a specific event at the general level, which cannot produce specific details. Thus, instead of an event, the response is a general type or category of events. The functional avoidance is seen as an active attempt not to find details of events or even specific events because of the negative affect they will produce. Impaired executive control also reduces the likelihood of finding specific events or details of events, much as it limits details in future episodic thought (D'Argembeau, Ortoleva, Jumentier, \& Van der Linden, 2010). The mechanisms work alone and together.

In terms of the explanation-based and similarity-based schematic construction mechanisms outlined, the model can be seen as using three maladaptive explanation-based mechanisms that have come to replace the similarity-based ones for past events. When specific memories cannot be assembled, the resulting more ab- stract ones are more subject to mood distortion and to abstract ruminative thoughts that fail to solve problems the way more specific future episodic thought can. People feel they are failures, not that they failed in a particular situation; that things always go wrong, not just this one time; and that no concrete solution can be found, only abstract attributions to the self. Therapies attempt to break the abstract pattern of thought that accompanies a lack of specific memories, often by using techniques that produce detailed, richer, embodied or situated events consistent with more similarity-based constructions or by changing the nature of the schemata of explanation-based constructions. It should be noted that the work reviewed earlier by Foa and Janoff-Bulman on the effects of traumatic events, on pain catastrophizing, and on the life script and CES can all be seen as primarily dealing with explanation-based problems with schemata.

In terms of the results presented in the literature and here, future memories also can be seen as less specific, and they may also be overgeneral. The mechanism of capture and rumination can be seen as parallel to focusing on the responses to the category of the event rather than its details. The mechanism of functional avoidance may play a smaller role except in very negative events and as an active form of inhibition would be more difficult to show in terms of experimental paradigms (MacLeod, 2007; MacLeod, Dodd, Sheard, Wilson, \& Bibi, 2003). The mechanism of impaired executive control can be seen as parallel to the need for increased effort and executive control to create a novel event. For negative and traumatic events, the similarities between the mechanisms of the CaR-FA-X model and the mechanisms that produce future episodic thought would be closer, as the CaR-FA-X model is primarily aimed at understanding overgeneral negative memories. Thus, future negative episodic thought, like overgeneral memories, can be viewed as the result of too much explanation-based schema construction. This could prevent more similarity-based construction that would lead to specific details rather than abstract similarities. The maladaptive nature of an overreliance on overgeneral memories can be lessened by training the individual to construct more specific memories or by changing the explanations of the explanation-based processes to be less problematic. Because a major function of memories and future episodic thought of negative events is to evaluate and plan, understanding their similarities could be of practical importance in changing behavior.

\section{Conclusions}

Future episodic thought is a theoretically and practically important area of study. Here, I have tried to expand its theoretical perspective by including the literature from schema theory, autobiographical memory, and clinical psychology. Many findings were replicated and extended in doing so, and support for them was increased by including independent evidence from other areas of research. Limitations of the current theoretical approach were challenged experimentally; however, the basic view that memories of past events and imagination of future events are the result of similar behavioral and neural process was consistently supported. Findings on future episodic thought and of clinical syndromes that depend on expectations about future events are remarkably similar, and this suggests the need for and benefit of more theoretical integration. 


\section{References}

Addis, D. R., Wong, A. T., \& Schacter, D. L. (2008). Age-related changes in the episodic simulation of future events. Psychological Science, 19, 33-41. doi:10.1111/j.1467-9280.2008.02043.x

Ahn, W., Brewer, W. F., \& Mooney, R. J. (1992). Schema acquisition from a single example. Journal of Experimental Psychology: Learning, Memory, and Cognition, 18, 391-412. doi:10.1037/0278-7393.18.2.391

Alba, J. W., \& Hasher, L. (1983). Is memory schematic? Psychological Bulletin, 93, 203-231. doi:10.1037/0033-2909.93.2.203

American Psychiatric Association. (2000). Diagnostic and statistical manual of mental disorders (4th ed., text rev.). Washington, DC: Author.

Bartlett, F. C. (1932). Remembering: A study in experimental and social psychology. London, England: Cambridge University Press.

Beike, D. R., Adams, L. P., \& Naufel, K. Z. (2010). Closure of autobiographical memories moderates their directive effect on behavior. Memory, 18, 40-48. doi:10.1080/09658210903405729

Beike, D. R., \& Wirth-Beaumont, E. T. (2005). Psychological closure as a memory phenomenon. Memory, 13, 574-593. doi:10.1080/ 09658210444000241

Berntsen, D., \& Bohn, A. (2010). Remembering and forecasting: The relation between autobiographical memory and episodic future thinking. Memory \& Cognition, 38, 265-278. doi:10.3758/MC.38.3.265

Berntsen, D., \& Jacobsen, A. S. (2008). Involuntary (spontaneous) mental time travel into the past and future. Consciousness and Cognition, 17, 1093-1104. doi:10.1016/j.concog.2008.03.001

Berntsen, D., \& Rubin, D. C. (2004). Cultural life scripts structure recall from autobiographical memory. Memory \& Cognition, 32, 427-442. doi:10.3758/BF03195836

Berntsen, D., \& Rubin, D. C. (2006). The Centrality of Event Scale: A measure of integrating a trauma into one's identity and its relation to post-traumatic stress disorder symptoms. Behaviour Research and Therapy, 44, 219-231. doi:10.1016/j.brat.2005.01.009

Berntsen, D., \& Rubin, D. C. (2007). When a trauma becomes a key to identity: Enhanced integration of trauma memories predicts posttraumatic stress disorder symptoms. Applied Cognitive Psychology, 21, 417-431. doi:10.1002/acp. 1290

Berntsen, D., Rubin, D. C., \& Siegler, I. C. (2011). Two versions of life: Emotionally negative and positive life events have different roles in the organization of life story and identity. Emotion, 11, 1190-1201. doi: $10.1037 / \mathrm{a} 0024940$

Blanchard, E. B., Jones-Alexander, J., Buckley, T. C., \& Foneris, C. A. (1996). Psychometric properties of the PTSD Checklist (PCL). Behaviour Research and Therapy, 34, 669-673. doi:10.1016/00057967(96)00033-2

Blaxton, T. A. (1989). Investigating dissociations among memory measures: Support for a transfer appropriate processing framework. Journal of Experimental Psychology: Learning, Memory, and Cognition, 15, 657-668. doi:10.1037/0278-7393.15.4.657

Boals, A., Banks, J. B., Hathaway, L. M., \& Schuettler, D. (2011). Coping with stressful events: Use of cognitive words in stressful narratives and the meaning-making process. Journal of Social and Clinical Psychology, 30, 378-403. doi:10.1521/jscp.2011.30.4.378

Bohn, A., \& Berntsen, D. (2011). The reminiscence bump reconsidered: Children's prospective life stories show a bump in young adulthood. Psychological Science, 22, 197-202. doi:10.1177/0956797610395394

Botzung, A., Denkova, E., \& Manning, L. (2008). Experiencing past and future personal events: Functional neuroimaging evidence on the neural bases of mental time travel. Brain and Cognition, 66, 202-212. doi: 10.1016/j.bandc.2007.07.011

Bransford, J. D., McCarrell, N. S., Franks, J. J., \& Nitsch, K. E. (1977). Toward unexplaining memory. In R. Shaw \& J. D. Bransford (Eds.), Perceiving, acting, and knowing: Toward an ecological psychology (pp. 431-466). Hillsdale, NJ: Erlbaum.

Brewer, W. F., \& Nakamura, G. V. (1984). The nature and function of schemas. In R. S. Wyer Jr. \& T. K. Skrull (Eds.), Handbook of social cognition (Vol. 1, pp. 119-160). Hillsdale, NJ: Erlbaum.

Brown, A. D., Root, J. C., Romano, T. A., Chang, L. J., Bryant, R. A., \& Hirst, W. (2013). Overgeneralized autobiographical memory and future thinking in combat veterans with posttraumatic stress disorder. Journal of Behavior Therapy and Experimental Psychiatry, 44, 129-134. doi: 10.1016/j.jbtep.2011.11.004

Buckner, R. L., \& Carroll, D. C. (2007). Self-projection and the brain. Trends in Cognitive Sciences, 11, 49-57. doi:10.1016/j.tics.2006.11.004

Cabeza, R., \& St. Jacques, P. (2007). Functional neuroimaging of autobiographical memory. Trends in Cognitive Sciences, 11, 219-227. doi: 10.1016/j.tics.2007.02.005

Cronbach, L. J. (1957). Two disciplines of scientific psychology. American Psychologist, 12, 671-684. doi:10.1037/h0043943

D'Argembeau, A. (2012). Autobiographical memory and future thinking. In D. Berntsen \& D. C. Rubin (Eds.), Understanding autobiographical memory: Theories and approaches (pp. 311-330). Cambridge, England: Cambridge University Press. doi:10.1017/CBO9781139021937.022

D'Argembeau, A., \& Mathy, A. (2011). Tracking the construction of episodic future thought. Journal of Experimental Psychology: General, 140, 258-271. doi:10.1037/a0022581

D'Argembeau, A., Ortoleva, C., Jumentier, S., \& Van der Linden, M. (2010). Component processes underlying future thinking. Memory \& Cognition, 38, 809-819. doi:10.3758/MC.38.6.809

D’Argembeau, A., Raffard, S., \& Van Der Linden, M. (2008). Remembering the past and imagining the future in schizophrenia. Journal of Abnormal Psychology, 117, 247-251. doi:10.1037/0021-843X.117.1 .247

D'Argembeau, A., Renaud, O., \& Van der Linden, M. (2011). Frequency, characteristics, and functions of future-oriented thoughts in daily life. Applied Cognitive Psychology, 25, 96-103. doi:10.1002/acp.1647

D'Argembeau, A., \& Van der Linden, M. (2004). Phenomenal characteristics associated with projecting oneself back into the past and forward into the future: Influence of valence and temporal distance. Consciousness and Cognition, 13, 844-858. doi:10.1016/j.concog.2004.07.007

D'Argembeau, A., \& Van der Linden, M. (2006). Individual differences in the phenomenology of mental time travel: The effect of vivid visual imagery and emotion regulation strategies. Consciousness and Cognition, 15, 342-350. doi:10.1016/j.concog.2005.09.001

Daselaar, S. M., Rice, H. J., Greenberg, D. L., Cabeza, R., LaBar, K. S., \& Rubin, D. C. (2008). The spatiotemporal dynamics of autobiographical memory: Neural correlates of recall, emotional intensity, and reliving. Cerebral Cortex, 18, 217-229. doi:10.1093/cercor/bhm048

Ebbinghaus, H. (1964). Memory: A contribution to experimental psychology (H. A. Ruger \& C. E. Bussenius, Trans.). New York, NY: Dover. (Original work published 1885)

Ehlers, A., \& Clark, D. M. (2000). A cognitive model of posttraumatic stress disorder. Behaviour Research and Therapy, 38, 319-345. doi: 10.1016/S0005-7967(99)00123-0

Ericsson, K. A., \& Simon, H. A. (1993). Protocol analysis: Verbal reports as data (Rev. ed.). Cambridge, MA: MIT Press.

Finnbogadóttir, H., \& Berntsen, D. (2013). Involuntary future projections are as frequent as involuntary memories, but more positive. Conscious ness and Cognition, 22, 272-280. doi:10.1016/j.concog.2012.06.014

Foa, E. B., \& Kozak, M. J. (1986). Emotional processing of fear: Exposure to corrective information. Psychological Bulletin, 99, 20-35. doi: 10.1037/0033-2909.99.1.20

Foa, E. B., Steketee, G., \& Rothbaum, B. O. (1989). Behavioral/cognitive conceptualization of post-traumatic stress disorder. Behavior Therapy, 20, 155-176. doi:10.1016/S0005-7894(89)80067-X

Fredrickson, B. L. (2001). The role of positive emotions in positive psychology: The broaden-and-build theory of positive emotions. American Psychologist, 56, 218-226. doi:10.1037/0003-066X.56.3.218 
Fredrickson, B. L., \& Branigan, C. (2005). Positive emotions broaden the scope of attention and thought-action repertoires. Cognition \& Emotion, 19, 313-332. doi:10.1080/02699930441000238

Greenberg, D. L., \& Rubin, D. C. (2003). The neuropsychology of autobiographical memory. Cortex, 39, 687-728. doi:10.1016/S00109452(08)70860-8

Hassabis, D., \& Maguire, E. A. (2007). Deconstructing episodic memory with construction. Trends in Cognitive Sciences, 11, 299-306. doi: 10.1016/j.tics.2007.05.001

Hintzman, D. L. (1986). "Schema abstraction" in a multiple-trace memory model. Psychological Review, 93, 411-428. doi:10.1037/0033-295X.93 .4 .411

Janoff-Bulman, R. (1989). Assumptive worlds and the stress of traumatic events: Applications of the schema construct. Social Cognition, 7, 113136. doi:10.1521/soco.1989.7.2.113

John, O. P., Donahue, E. M., \& Kentle, R. L. (1991). The Big Five Inventory-Versions $4 a$ and 54. Berkeley: University of California, Berkeley, Institute of Personality and Social Psychology.

John, O. P., \& Srivastava, S. (1999). The Big Five trait taxonomy: History, measurement, and theoretical perspectives. In L. A. Pervin \& O. P. John (Eds.), Handbook of personality: Theory and research (Vol. 2, pp. 102-138). New York, NY: Guilford Press.

Keefe, F. J., Brown, G. K., Wallston, K. A., \& Caldwell, D. S. (1989). Coping with rheumatoid arthritis: Catastrophizing as a maladaptive strategy. Pain, 37, 51-56. doi:10.1016/0304-3959(89)90152-8

Larsen, S. F. (1998). What is it like to remember? On the phenomenal qualities of memory. In C. P. Thompson, D. J. Herrmann, D. Bruce, J. D. Read, D. G. Payne, \& M. P. Toglia (Eds.), Autobiographical memory: Theoretical and applied perspectives (pp. 163-190). Mahwah, NJ: Erlbaum.

Maccallum, F., \& Bryant, R. A. (2011). Imagining the future in complicated grief. Depression and Anxiety, 28, 658-665. doi:10.1002/da .20866

MacLeod, C. M. (2007). The concept of inhibition in cognition. In D. S. Gorfein \& C. M. MacLeod (Eds.), Inhibition in cognition (pp. 3-23). Washington, DC: American Psychological Association.

MacLeod, C. M., Dodd, M. D., Sheard, E. D., Wilson, D. E., \& Bibi, U. (2003). In opposition to inhibition. Psychology of Learning and Motivation, 43, 163-214.

Miles, A. N. (in press). Cuing methodologies in mental time travel. Nordic Psychology.

Miles, A. N., \& Berntsen, D. (2011). Odour-induced mental time travel into the past and future: Do odour cues retain a unique link to our distant past? Memory, 19, 930-940. doi:10.1080/09658211.2011.613847

Newby-Clark, I. R., \& Ross, M. (2003). Conceiving the past and future. Personality and Social Psychology Bulletin, 29, 807-818. doi:10.1177/ 0146167203029007001

Perri, L. M., \& Keefe, F. J. (2008). Applying centrality of event to persistent pain: A preliminary view. Pain, 9, 265-271. doi:10.1016/j .jpain.2007.10.019

Rasmussen, K. W. (in press). The role of the hippocampus and prefrontal cortex in imagining the future: Insights from lesion studies. Nordic Psychology

Rubin, D. C. (1995). Memory in oral traditions: The cognitive psychology of epic, ballads, and counting-out rhymes. New York, NY: Oxford University Press.

Rubin, D. C. (2006). The basic-systems model of episodic memory. Perspectives on Psychological Science, 1, 277-311. doi:10.1111/j.17456916.2006.00017.x

Rubin, D. C. (2012). The basic systems model of autobiographical memory. In D. Berntsen \& D. C. Rubin (Eds.), Understanding autobiographical memory: Theories and approaches (pp. 11-32). Cambridge, England: Cambridge University Press. doi:10.1017/CBO9781139021937 .004
Rubin, D. C., Berntsen, D., \& Bohni, M. K. (2008). A memory-based model of posttraumatic stress disorder: Evaluating basic assumptions underlying the PTSD diagnosis. Psychological Review, 115, 985-1011. doi:10.1037/a0013397

Rubin, D. C., Boals, A., \& Berntsen, D. (2008). Memory in posttraumatic stress disorder: Properties of voluntary and involuntary, traumatic and non-traumatic autobiographical memories in people with and without PTSD symptoms. Journal of Experimental Psychology: General, 137 591-614. doi:10.1037/a0013165

Rubin, D. C., Dennis, M. F., \& Beckham, J. C. (2011). Autobiographical memory for stressful events: The role of autobiographical memory in posttraumatic stress disorder. Consciousness and Cognition, 20, 840856. doi:10.1016/j.concog.2011.03.015

Rubin, D. C., \& Feeling, N. (in press). Measuring the severity of negative and traumatic events. Clinical Psychological Science.

Rubin, D. C., \& Kontis, T. C. (1983). A schema for common cents. Memory \& Cognition, 11, 335-341. doi:10.3758/BF03202446

Rubin, D. C., Schrauf, R. W., \& Greenberg, L. (2003). Belief and recollection of autobiographical memories. Memory \& Cognition, 31, 887901. doi:10.3758/BF03196443

Rubin, D. C., Schrauf, R. W., \& Greenberg, D. L. (2004). Stability in autobiographical memories. Memory, 12, 715-721. doi:10.1080/ 09658210344000512

Rubin, D. C., \& Siegler, I. C. (2004). Facets of personality and the phenomenology of autobiographical memory. Applied Cognitive Psychology, 18, 913-930. doi:10.1002/acp.1038

Rubin, D. C., Stoltzfus, E. R., \& Wall, K. L. (1991). The abstraction of form in semantic categories. Memory \& Cognition, 19, 1-7. doi:10.3758/ BF03198491

Rubin, D. C., Wallace, W. T., \& Houston, B. C. (1993). The beginnings of expertise for ballads. Cognitive Science, 17, 435-462. doi:10.1207/ s15516709 $\operatorname{cog} 1703 \_4$

Rumelhart, D. E., Smolensky, P., McClelland, J. L., \& Hinton, G. E (1986). Schemata and sequential thought processes in PDP models. In J. L. McClelland, D. E. Rumelhart, \& the PDP Research Group (Eds.), Parallel distributed processing: Explorations in the microstructure of cognition. Vol. 2: Psychological and biological models (pp. 7-57). Cambridge, MA: MIT Press.

Schacter, D. L., \& Addis, D. R. (2007). The cognitive neuroscience of constructive memory: Remembering the past and imagining the future. Philosophical Transactions of the Royal Society of London B: Biological Sciences, 362, 773-786. doi:10.1098/rstb.2007.2087

Schacter, D. L., \& Addis, D. R. (2009). On the nature of medial temporal lobe contributions to the constructive simulation of future events. Philosophical Transactions of the Royal Society of London B: Biological Sciences, 364, 1245-1253. doi:10.1098/rstb.2008.0308

Schank, R. C., \& Abelson, R. P. (1995). Knowledge and memory: The real story. In R. S. Wyer Jr. (Ed.), Knowledge and memory: The real story (pp. 1-85). Hillsdale, NJ: Erlbaum.

Spreng, R. N., \& Grady, C. L. (2010). Patterns of brain activity supporting autobiographical memory, prospection, and theory-of-mind and their relationship to the default mode network. Journal of Cognitive Neuroscience, 22, 1112-1123. doi:10.1162/jocn.2009.21282

Spreng, R. N., \& Levine, B. (2006). The temporal distribution of past and future autobiographical events across the lifespan. Memory \& Cognition, 34, 1644-1651. doi:10.3758/BF03195927

Spreng, R. N., Mar, R. A., \& Kim, A. S. N. (2009). The common neural basis of autobiographical memory, prospection, navigation, theory of mind, and the default mode: A quantitative meta-analysis. Journal of Cognitive Neuroscience, 21, 489-510. doi:10.1162/jocn.2008.21029

St. Jacques, P. L, (2012). Functional neuroimaging of autobiographical memory. In D. Berntsen \& D. C. Rubin. (Eds.), Understanding autobiographical memory: Theories and approaches (pp. 114-138). Cam- 
bridge, England: Cambridge University Press. doi:10.1017/ CBO9781139021937.010

St. Jacques, P. L., Botzung, A., Miles, A., \& Rubin, D. C. (2011). Functional neuroimaging of emotionally intense autobiographical memories in posttraumatic stress disorder. Journal of Psychiatric Research, 45, 630-637. doi:10.1016/j.jpsychires.2010.10.011

Sullivan, M. J., Thorn, B., Haythornthwaite, J. A., Keefe, F., Martin, M., Bradley, L. A., \& Lefebvre, J. C. (2001). Theoretical perspectives on the relation between catastrophizing and pain. Clinical Journal of Pain, 17, 52-64. doi:10.1097/00002508-200103000-00008

Svoboda, E., McKinnon, M. C., \& Levine, B. (2006). The functional neuroanatomy of autobiographical memory: A meta-analysis. Neuropsychologia, 44, 2189-2208. doi:10.1016/j.neuropsychologia.2006.05.023

Szpunar, K. K. (2010). Episodic future thought: An emerging concept. Perspectives on Psychological Science, 5, 142-162. doi:10.1177/ 1745691610362350

Szpunar, K. K., \& McDermott, K. B. (2008). Episodic future thought and its relation to remembering: Evidence from ratings of subjective experience. Consciousness and Cognition, 17, 330-334. doi:10.1016/j .concog.2007.04.006

Talarico, J. M., Berntsen, D., \& Rubin, D. C. (2009). Positive emotions enhance recall of peripheral details. Cognition \& Emotion, 23, 380-398. doi:10.1080/02699930801993999

Taylor, S. E. (1991). Asymmetrical effect of positive and negative events: The mobilization-minimization hypothesis. Psychological Bulletin, 110, 67-85. doi:10.1037/0033-2909.110.1.67

Taylor, S. E., \& Brown, J. D. (1988). Illusion and well-being: A social psychological perspective on mental health. Psychological Bulletin, 103, 193-210. doi:10.1037/0033-2909.103.2.193

Taylor, S. E., Pham, L. B., Rivkin, I. D., \& Armor, D. A. (1998). Harnessing the imagination: Mental simulation, self-regulation, and coping. American Psychologist, 53, 429-439. doi:10.1037/0003-066X.53.4 .429

Trope, Y., \& Liberman, N. (2010). Construal-level theory of psychological distance. Psychological Review, 117, 440-463. doi:10.1037/a0018963

Tulving, E. (1972). Episodic and semantic memory. In E. Tulving \& W. Donaldson (Eds.), Organization of memory (pp. 381-403). New York, NY: Academic Press.
Tulving, E. (1983). Elements of episodic memory. New York, NY: Oxford University Press.

Tulving, E. (1985). Memory and consciousness. Canadian Psychology, 26 , 1-12. doi:10.1037/h0080017

Tulving, E. (2002). Episodic memory: From mind to brain. Annual Review of Psychology, 53, 1-25. doi:10.1146/annurev.psych.53.100901.135114

Van Boven, L., \& Ashworth, L. (2007). Looking forward, looking back: Anticipation is more evocative than retrospection. Journal of Experimental Psychology: General, 136, 289-300. doi:10.1037/0096-3445 136.2.289

Walker, W. R., Skowronski, J. J., \& Thompson, C. P. (2003). Life is pleasant-And memory helps to keep it that way! Review of General Psychology, 7, 203-210. doi:10.1037/1089-2680.7.2.203

Weathers, F. W., Litz, B. T., Huska, J. A., \& Keane, T. M. (1994). The PTSD Checklist $(P C L)$. Unpublished manuscript, National Center for PTSD.

Wenzel, A., Pinna, K., \& Rubin, D. C. (2004). Autobiographical memories of anxiety-related experiences. Behaviour Research and Therapy, 42, 329-341. doi:10.1016/S0005-7967(03)00142-6

Wheeler, M. A., Stuss, D. T., \& Tulving, E. (1997). Toward a theory of episodic memory: The frontal lobes and autonoetic consciousness. Psychological Bulletin, 121, 331-354. doi:10.1037/0033-2909.121.3.331

Williams, J. M. G., Barnhofer, T., Crane, C., Herman, D., Raes, F., Watkins, E., \& Dalgleish, T. (2007). Autobiographical memory specificity and emotional disorder. Psychological Bulletin, 133, 122-148. doi:10.1037/0033-2909.133.1.122

Williams, J. M. G., Ellis, N. C., Tyers, C., Healy, H., Rose, G., \& MacLeod, A. K. (1996). The specificity of autobiographical memory and imaginability of the future. Memory \& Cognition, 24, 116-125. doi: 10.3758/BF03197278

Williams, J. M. G., Watts, F. N., MacLeod, C., \& Mathews, A. (1997). Cognitive psychology and emotional disorders (2nd ed.). Chichester, England: Wiley.
Received October 22, 2012

Revision received March 6, 2013

Accepted March 8, 2013 